\title{
New Anthribidae (Coleoptera: Curculionoidea) in Dominican and Mexican ambers
}

\author{
George Poinar, Jr. and Andrei A. Legalov
}

\begin{abstract}
Eighteen new species of the family Anthribidae are described from Dominican and Mexican amber. These include: Euparius elongatus sp. nov. in the tribe Cratoparini, Toxonotus comatus sp. nov. in the tribe Platystomini, Eugonus adustus sp. nov. and $E$. angustus sp. nov. in the tribe Eugonini, Piesocorynus unibullus sp. nov., P. bibullus sp. nov., $P$. tribullus sp. nov., $P$. brevitectus sp. nov., $P$. hamus sp. nov., $P$. elongatus sp. nov., P. parategus sp. nov., P.villosus sp. nov., P. parvocorpus sp. nov., Piezobarra brevisensoriata sp. nov. in the tribe Piesocorynini, Choragus exsertus sp. nov. in the tribe Choragini, Neoxenus globosus sp. nov., Cyptoxenus buchelus sp. nov. and C. ovatus sp. nov. in the tribe Valenfriesiini. These are the first records of the genera Eugonus, Piezobarra, Choragus, Neoxenus and Cyptoxenus in the fauna of Hispaniola. The genera Toxonotus, Eugonus, Piesocorynus, Piezobarra, Neoxenus and Cyptoxenus are reported in the fossil state for the first time. These new taxa further demonstrate the diversity of the Curculionoidea fauna in New World amber.
\end{abstract}

George Poinar, Jr. Department of Integrative Biology, Oregon State University, Corvallis, Oregon 97331, USA.poinarg@science.oregonstate.edu

Andrei A. Legalov. Laboratory of Phylogeny and Faunogenesis, Institute of Systematics and Ecology of Animals, Siberian Branch, Russian Academy of Sciences, Frunze street, 11, Novosibirsk 630091, Russia. fossilweevils@gmail.com

Keywords: Anthribinae; Choraginae; new species; fossils; Miocene

Submission: 26 January 2016. Acceptance: 19 June 2016

\section{INTRODUCTION}

Fungus weevils (Anthribidae) are a monophyletic family with about 4000 species from more than 300 genera (Rheinheimer, 2004; Legalov, 2015) attributable to five subfamilies (Legalov, 2015). The modern anthribid fauna is widespread, but reaches the greatest diversity in the tropics. The larvae develop in ligneous fungi, seeds, stem galls, etc. (Louw, 1993; Kuschel, 1995; Valentine, 1999). Fossils of this group are poorly known, primarily due to the hidden habits of the adults.

http://zoobank.org/74027BAE-E2E4-4DD0-8127-D06BFA1C5DE7

Poinar, George, Jr. and Legalov, Andrei A. 2016. New Anthribidae (Coleoptera: Curculionoidea) in Dominican and Mexican ambers. Palaeontologia Electronica 19.2.24A: 1-38

palaeo-electronica.org/content/2016/1519-new-anthribidae-in-ambers

Copyright: July 2016 Palaeontological Association 
Dating of Dominican amber is controversial with the latest purported age of 20-15 Ma based on foraminifera (Iturralde-Vinent and MacPhee, 1996) and the earliest of 45-30 Ma based on coccoliths (Schlee, 1990). In addition, Dominican amber is secondarily deposited in sedimentary rocks, which makes a definite age determination difficult (Poinar and Mastalerz, 2000). A range of ages for Dominican amber is possible as the amber is associated with turbiditic sandstones of the Upper Eocene to Lower Miocene Mamey Group (Draper et al., 1994). Dominican amber was produced by the leguminous tree, Hymenaea protera Poinar (Poinar, 1991) and a re-construction of the Dominican amber forest based on amber fossils indicated that the environment was similar to that of a present-day tropical moist forest (Poinar and Poinar, 1999). Amber from Chiapas, which was produced by Hymenaea mexicana (Fabaceae) (Poinar and Brown, 2002), occurs in lignitic beds among sequences of primarily marine calcareous sandstonesand silt. The amber is associated with La Quinta Formation, Balumtun Sandstone and Mazantic Shale with radiometric ages from 15 to 20 million years (Solórzano Kraemer, 2007). Since the amber is secondarily deposited in these marine formations, it may be somewhat older than the above dates.

The present study describes representatives of Anthribidae from Dominican and Mexican amber, including a new species of the genus Euparius Schoenherr, 1823 in the tribe Cratoparini, a new species of the genus Toxonotus Lacordaire, 1866 in the tribe Platystomini, two new species of the genus Eugonus Lacordaire, 1866 in the tribe Eugonini, nine new species of the genus Piesocorynus Dejean, 1834 and a new species of the genus Piezobarra in the tribe Piesocorynini, a new species of the genus Choragus Kirby, 1819 in the tribe Choragini, a new species of the genus Neoxenus Valentine, 1999 and two new species of Cyptoxenus Valentine, 1982 in the tribe Valenfriesiini.

\section{MATERIALS AND METHODS}

The specimens were obtained from amber mines in the Cordillera Septentrional of the Dominican Republic and an amber mine in the northern mountain ranges of the Chiapas Highlands of the Simojovel area in Chiapas, Mexico. Most types are deposited in the Poinar amber collection maintained at Oregon State University (PACO, Corvallis, OR, USA). Two types are deposited in the Institute of Systematics and Ecology of Animals (ISEA, Novosibirsk, Russia) collection.
Descriptions and photographs were produced by the authors using a Nikon SMZ-10 stereoscopic microscope and Zeiss, Stemi-2000-C. Helicon Focus Pro X64 was used to stack photos for better clarity and depth of field. All measurements were made using an ocular micrometer.

\section{SYSTEMATIC PALAEONTOLOGY}

Family ANTHRIBIDAE Billberg, 1820

Subfamily ANTHRIBINAE Billberg, 1820

Tribe CRATOPARINI LeConte and Horn, 1876

Genus EUPARIUS Schoenherr, 1823

Euparius elongatus sp. nov.

Figure 1

zoobank.org/415D3038-20AF-48E3-AC55-A40ED496C45F

Holotype. Deposited in the PACO (accession \# C106).

Description. Length body, $4.9 \mathrm{~mm}$; length rostrum, $0.6 \mathrm{~mm}$. Body brown with covering of pale, appressed setae. Rostrum wide and short, 0.6 times as long as pronotum, flat; mandibles with small middle ventral tooth and large basal tooth; antennal scrobes foveiform lateral, slightly touching eyes; forehead wide, flattened, punctate; eyes large, circular, distinctly convex; vertex convex and punctate; temples quite short, 0.8 times as long as length of eye; antennae inserted at base of rostrum, quite long, almost reaching base of pronotum; club not compact, broad, 2.3 times longer than wide. Pronotum bell-shaped; 1.2 times longer than wide at apex, 0.9 times longer than wide in middle and at base, with quite long lateral carinae; disk flattened, densely and finely punctate; transverse dorsal pronotal carina basal; scutellum widetrapezoidal. Elytra elongate and distinctly convex, 2.4 times longer than wide at base, 2.6 times longer than wide in middle, 2.8 times longer than wide at apical fourth, 2.8 times as long as pronotum; greatest width of humeri behind middle; humeri weakly flattened; striae regular and thin; strial punctures small, rounded; elytral intervals convex, quite wide, 2.0-2.7 times as wide as striae, small and faintly punctate; second-fourth intervals distinctly convex in first quarter of elytra; apices of elytra not rounded; pygidium not concealed. Thorax faintly punctate; precoxal portion of prosternum elongate, 2.8 times as long as procoxal cavities, 4.0 times as long as postcoxal portion; postcoxal portion 0.7 times as long as procoxal cavities; procoxal cavities narrowly separated; mesocoxal cavities widely separated, metanepisternum quite narrow. Abdomen convex; first ventrite 0.9 times as long as length of metacoxal cavity; second ventrite 

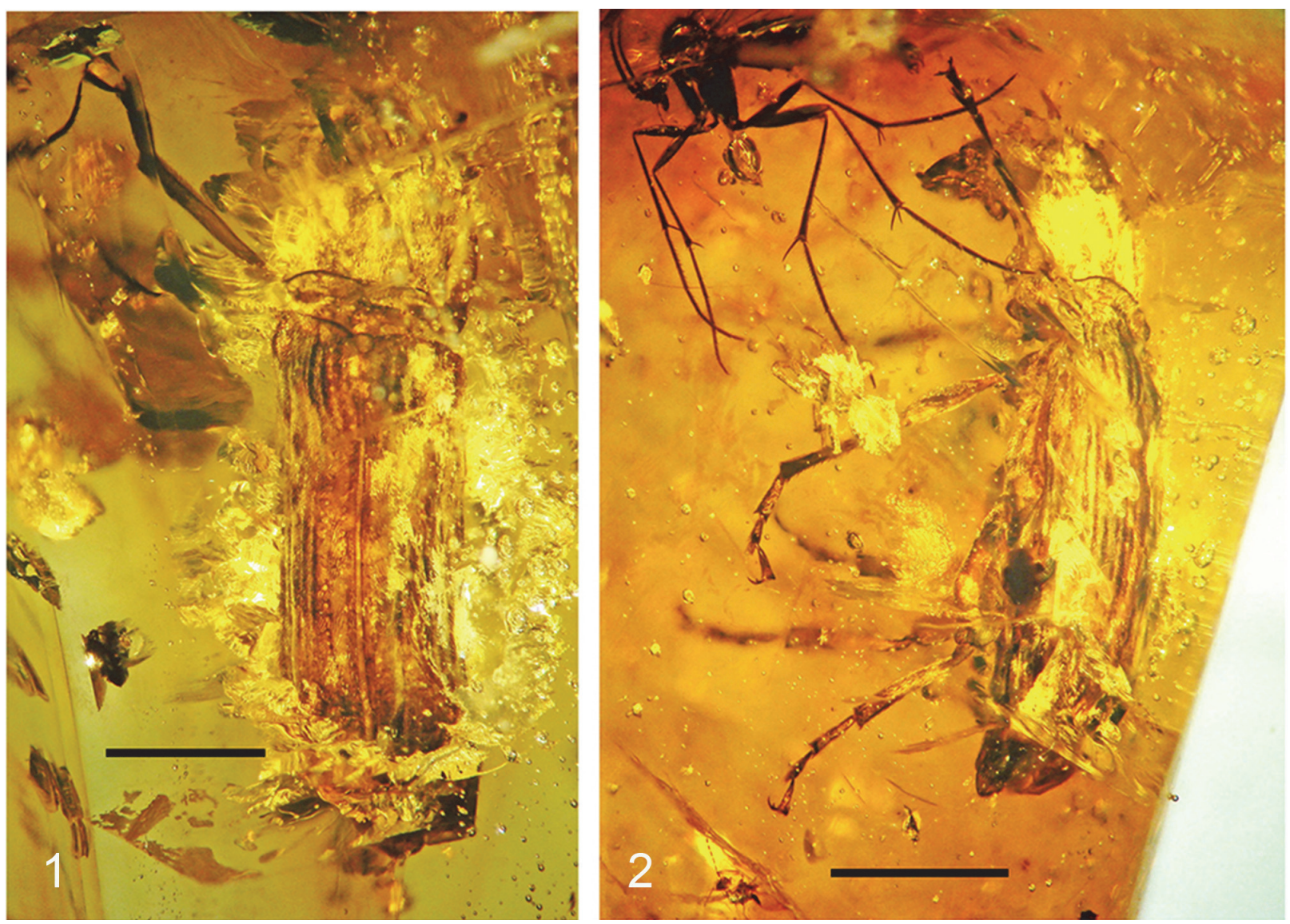

FIGURE 1. Holotype of Euparius elongatus sp. nov. PACO no. C-106 in Mexican amber. 1, dorsal view, scale bar equals $1.0 \mathrm{~mm}$; and $\mathbf{2}$, lateral view, scale bar equals $1.3 \mathrm{~mm}$.

1.1 times as long as length of first ventrite; third ventrite 0.8 times as long as length of second ventrite; fourth ventrite 0.9 times as long as length of third ventrite; fifth ventrite 1.8 times as long as length of fourth ventrite. Legs long; pro- and mesocoxae round; metacoxae transverse; femora clavate, without teeth; trochanters obconical; profemora 3.1 times longer than wide; mesofemora 3.9 times longer than wide; metafemora 4.1 times longer than wide; tibiae almost straight; protibiae 9.8 times longer than wide in middle; mesotibiae 10.3 times longer than wide in middle; metatibiae 6.0 times longer than wide in middle; tarsi long; all third tarsomeres separated; first and second tarsomeres to third tarsomeres conical; second tarsomere embracing third tarsomere laterally; fifth elongate; tarsomeres with pulvilli on underside; tarsal claws free, large, diverging, with basal teeth; protarsi: first tarsomere 2.5 times longer than wide at base; second tarsomere 1.4 longer than wide at base, 0.7 times as long as and 1.3 times as wide as first tarsomere; third tarsomere equal in length and width, 0.4 times as long as and 0.5 times as wide as second tarsomere; fifth tarsomere 4.8 times longer than wide at base, 3.0 times as long as and 0.6 times as wide as second tarsomere; mesotarsi: first tarsomere 2.3 times longer than wide at base; second tarsomere 1.3 times as long as first tarsomere; fifth tarsomere 3.7 times longer than wide at base; metatarsi: first tarsomere 4.7 times longer than wide at base; second tarsomere 0.9 times as long as first tarsomere; fifth tarsomere 3.7 times longer than wide at base.

Type locality. Amber mine in Chiapas Highlands of the Simojovel area in Chiapas, Mexico.

Etymology. The specific epithet is from the Latin "elongatus" equals long, in reference to the body form of the fossil.

Comparison. The new species is similar to $E$. apicalis (Fahraeus, 1839) from Brazil and French Guiana but differs by the smaller body size, narrower brown body, elytra without spots of setae and convex elytral intervals. From E. placidus (Jordan, 1937) from Central America, it differs by the narrower body, convex elytral intervals, and longer tarsi. 

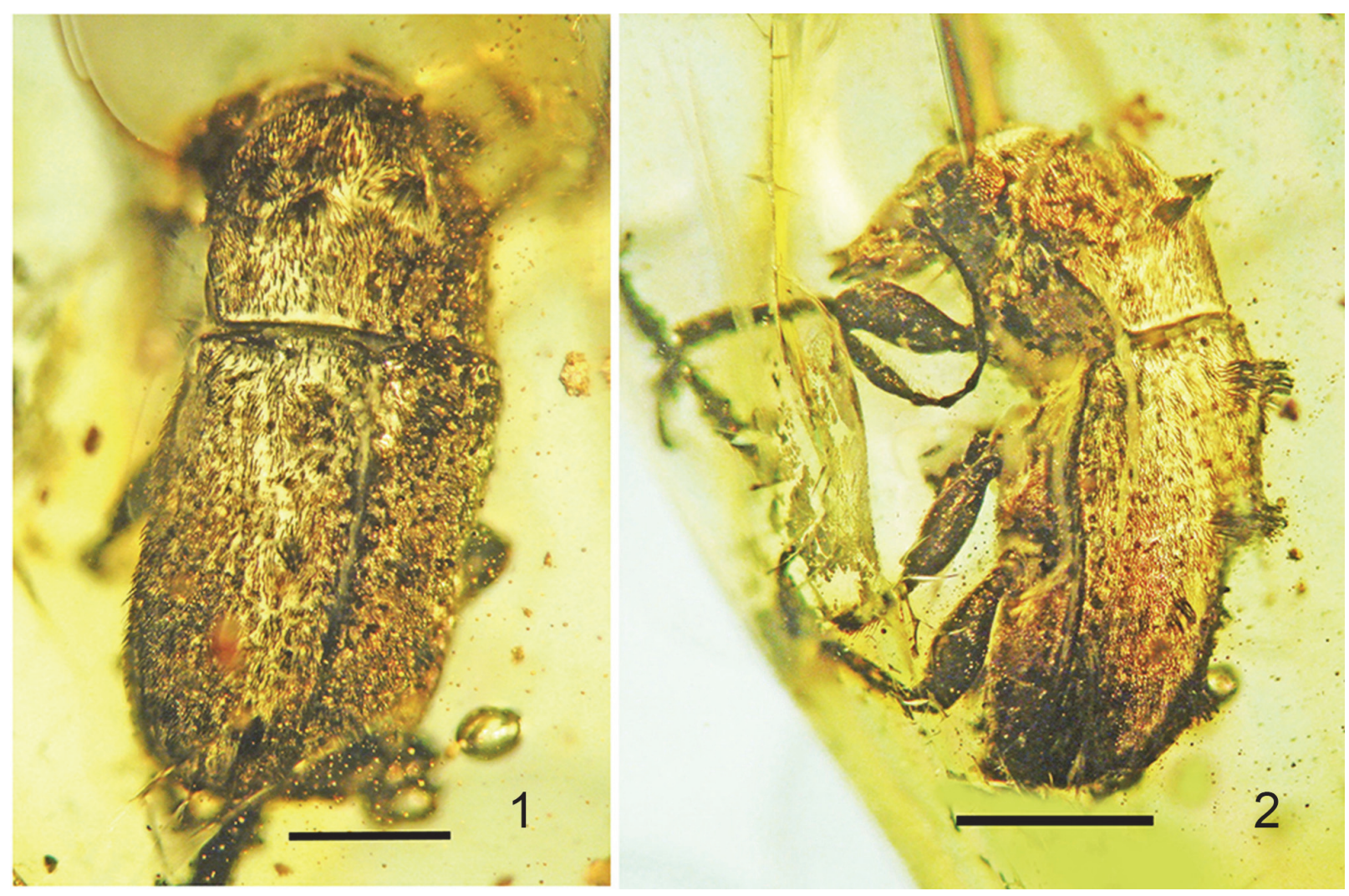

FIGURE 2. Holotype of Toxonotus comatus sp. nov. PACO no. C-100 in Dominican amber. 1, dorsal view, scale bar equals $1.0 \mathrm{~mm}$; and 2, lateral view, scale bar equals $1.2 \mathrm{~mm}$.

Remarks. The new species belongs to the genus Euparius of the tribe Cratoparini based on the mandibles with a small middle tooth on the ventral cutting edge and a large basal tooth, eyes circular and antennal scrobes slightly touching the eyes.

Tribe PLATYSTOMINI Pierce, 1916

Genus TOXONOTUS Lacordaire, 1866

Toxonotus comatus sp. nov.

Figure 2

zoobank.org/EB68A598-1A42-4009-940B-148049E68FDD

Holotype. Deposited in the PACO (accession \# C100).

Description. Length body, $4.3 \mathrm{~mm}$; length rostrum, $0.9 \mathrm{~mm}$. Body brownish-black with covering of distinct, dense, dark, semierect setae. Rostrum wide and short, 0.5 times as long as pronotum, flat, with dorsal median carina interrupted at base by transverse groove; antennal scrobes foveiform, lateral; forehead wide, flattened, punctate; eyes large, distinctly convex, 0.6 times longer than wide; vertex weakly convex and densely punctate; temples quite short, 0.5 times as long as length of eye; antennae inserted near base of rostrum, elongate, reaching humeri; first antennomere (scape) 2.5 times longer than wide; funicle with second to eighth antennomeres elongate-conical; second antennomere 4.0 times longer than wide, 1.2 times as long as and 0.8 times as narrow as first antennomere; third antennomere 4.1 times longer than wide, 0.8 times as long as and 0.7 times as narrow as second antennomere; third to sixth antennomeres subequal in width; fourth antennomere 4.5 times longer than wide, 0.9 times as long as third antennomere; fifth to eighth antennomeres subequal in length; fifth antennomere 3.6 times longer than wide, 0.9 times as long as fourth antennomere; sixth antennomere subequal to fifth antennomere; seventh antennomere 2.7 times longer than wide, 1.4 times as wide as sixth antennomere; eighth antennomere subequal to seventh antennomere; eighth antennomere 0.7 times longer than wide, 1.3 times as wide as seventh antennomere; club not compact, 4.8 times longer than wide, 0.5 times as long as funicle; first antennomere of club 2.3 times longer than wide, 1.8 times as long as and 2.0 times as wide as eighth antennomere; second antennomere of club 1.2 times longer than wide, 0.5 times as long as and equal in width to first antennomere of club; third antennomere of 
club 2.0 times longer than wide, 1.1 times as long as and 0.7 times as narrow as second antennomere of club. Pronotum bell-shaped; 1.3 times longer than wide at apex, 0.9 times longer than wide in middle and at base, with long lateral carinae; disk flattened, densely and finely punctate, with three black tufts of setae; apical margin of pronotum with pair of erect scale tufts; transverse dorsal pronotal carina basal; scutellum wide-trapezoidal. Elytra elongate and distinctly convex, 1.6 times longer than wide at base, 1.5 times longer than wide in middle, 2.0 times longer than wide at apical fourth, 2.0 times as long as pronotum; greatest width behind middle; elytron with four black tufts of setae; humeri weakly convex; striae regular and thin; strial punctures small, oval, dense; elytral intervals flattened, wide, 1.3-2.5 times as wide as striae, very small and finely punctate; apices of elytra not rounded; pygidium not concealed. Thorax punctate; precoxal portion of prosternum quite elongate, 1.7 times as long as procoxal cavities, 4.0 times as long as postcoxal portion; postcoxal portion 0.4 times as long as procoxal cavities; procoxal cavities separated; mesocoxal cavities widely separated, metanepisternum narrow. Abdomen weakly flattened ventrally; first ventrite 0.5 times as long as length of metacoxal cavities; second ventrite 1.5 times as long as length of first ventrite; third ventrite equal in length to second ventrite; fourth ventrite 0.8 times as long as length of third ventrite; fifth ventrite 1.1 times as long as length of fourth ventrite. Legs long, not villose with long white hairs; pro- and mesocoxae round; metacoxae transverse; femora clavate, without teeth; trochanters obconical; profemora 2.7 times longer than wide; mesofemora 3.1 times longer than wide; metafemora 3.0 times longer than wide; tibiae almost straight; protibiae 7.0 times longer than wide in middle; metatibiae 6.6 times longer than wide in middle; tarsi long; all third tarsomeres separate; first to third tarsomeres conical; second tarsomere embracing third tarsomere laterally; fifth tarsomere elongate; tarsomeres with pulvilli on underside; tarsal claws free, large, diverging, with basal teeth.

Type locality. Amber mine in the Cordillera Septentrional of the northern portion of the Dominican Republic.

Etymology. The specific epithet is taken from the Latin "comatus" equals hairy, in reference to the hairy elytra of the fossil.

Comparison. The new species is similar to T. cornutus (Say, 1831) from the USA and Mexico but differs by the elytron having four black setal tufts and elytra lacking white spots in upper third. From
T. penicellatus (Schaeffer, 1904) in North and Central America, it differs by the smaller setal tufts on the pronotum, dark setae on the body and a short, wide pronotum.

Remarks. The foveiform scrobes, basal transverse dorsal pronotal carina and rostrum with a dorsal median carina interrupted at the base by transverse groove are features of the tribe Platystomini. The new species belongs to the genus Toxonotus based on having all third tarsomeres separate.

Tribe EUGONINI Lacordaire, 1866, stat. res.

Remarks. The tribe Eugonini was reduced to a synonym of the tribe Basitropidini (Alonso-Zarazaga and Lyal, 2002) when Valentine (1999) included the genus Eugonus Schoenherr, 1833 in the latter tribe. One of the most important features separating the tribes of the family Anthribidae is the position and shape of the antennal scrobes (Morimoto, 1972). The sulciform scrobes are common to both tribes, but the Eugonini have dorso-lateral, antennal scrobes contiguous with eyes while the Basitropidini have latero-ventral antennal scrobes distant from the eye. The Eugonini differ from the tribe Corrhecerini by the foveiform scrobes and the lateral carina of the pronotum that extends to the anterior margin. The genera Corrhecerus Schoenherr, 1826, Nemotrichus Labram and Imhoff, 1838, and Phaenithon Schoenherr, 1826 are placed in the tribe Corrhecerini.

\section{Genus EUGONUS Lacordaire, 1866 \\ Eugonus adustus sp. nov. Figure 3}

\section{zoobank.org/0D665EED-1B2E-446C-B090-7071353B7361}

Holotype. Deposited in the PACO (accession \# C99).

Description. Length body, $3.1 \mathrm{~mm}$; length rostrum, $0.5 \mathrm{~mm}$. Body brownish-black with covering of quite distinct, dense, pale, appressed setae. Rostrum wide and short, 0.5 times as long as pronotum, flat, without dorsal median carina; antennal scrobes sulciform, dorso-lateral, contiguous with eyes; forehead wide, weakly convex, punctate; eyes large, rounded, distinctly convex, 1.2 times longer than wide; vertex weakly convex, densely punctate; temples short; antennae inserted at base of rostrum, quite long, almost reaching middle of pronotum; flagellum black; antennal club not compact, 2.7 times longer than wide. Pronotum almost bell-shaped; 2.0 times longer than wide at apex, 1.1 times longer than wide in middle and at base, with long lateral carina reaching front margin of pronotum; disk weakly convex, densely and finely punctate; faint transverse dorsal pronotal carina 

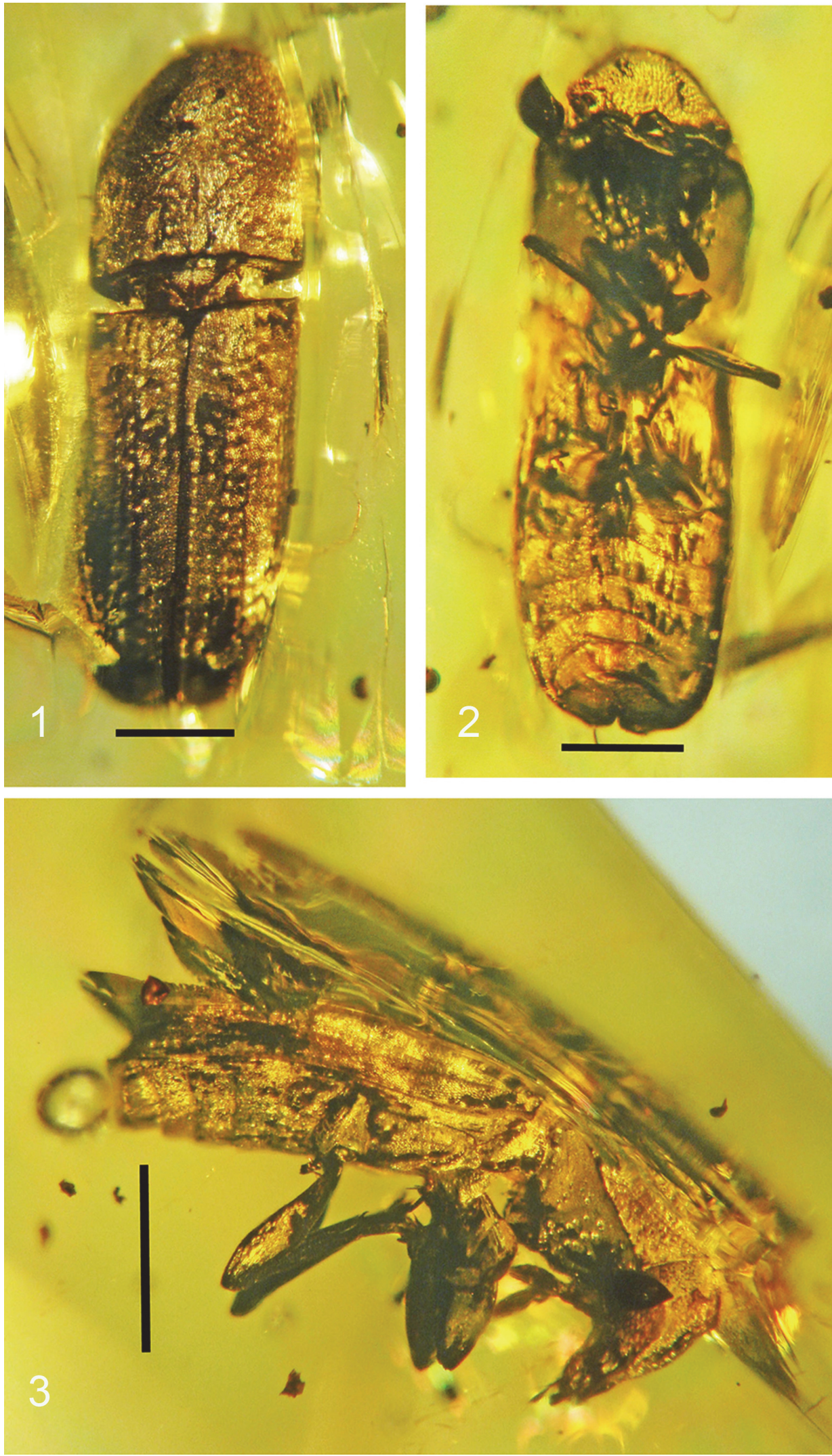

FIGURE 3. Holotype of Eugonus adustus sp. nov. PACO no. C-99 in Dominican amber. 1, dorsal view, scale bar equals $0.6 \mathrm{~mm} ; 2$, ventral view, scale bar equals $0.6 \mathrm{~mm}$; and 3 , lateral view, scale bar equals $0.9 \mathrm{~mm}$. 
basal; scutellum trapezoidal. Elytra cylindrical, elongate and distinctly convex, 1.9 times longer than wide at base and in middle, 2.2 times longer than wide at apical fourth, 1.9 times as long as pronotum, without setae; greatest width in middle; humeri weakly flattened; striae regular and distinct; strial punctures oval, dense; elytral intervals weakly convex, 1.0-1.5 times as wide as striae, finely punctate; apices of elytra not rounded; pygidium not concealed. Thorax punctate; precoxal portion of prosternum quite elongate, 1.3 times as long as procoxal cavities, 3.1 times as long as postcoxal portion; postcoxal portion 0.5 times as long as procoxal cavities; procoxal cavities narrowly separated; mesocoxal cavities widely separated; metaventrite finely punctate, metanepisternum narrow, 8.8 times longer than wide in middle. Abdomen convex; first ventrite 0.8 times as long as length of metacoxal cavity; second ventrite 1.5 times longer than length of first ventrite; third ventrite 0.8 times as long as length of second ventrite; fourth ventrite 0.8 times as long as length of third ventrite; fifth ventrite 1.1 times as long as length of fourth ventrite. Legs long; pro- and mesocoxae round; metacoxae transverse; femora clavate, without teeth; trochanters obconical; mesofemora 3.8 times longer than wide; metafemora 3.8 times longer than wide; tibiae black, flattened, almost straight; metatibiae 8.4 times longer than wide in middle; tarsi long, black; first to third tarsomeres conical; second tarsomere embracing third tarsomere laterally; fifth elongate; tarsomeres with pulvilli on underside; tarsal claws free, large, distinct diverging, with basal teeth.

Type locality. Amber mine in the Cordillera Septentrional of the northern portion of the Dominican Republic.

Etymology. The specific epithet is taken from the Latin "adustus" equals dark brown, in reference to the color of the fossil.

Comparison. The new species is similar to $E$. ornatus Jordan, 1904 from Brazil but differs by the smaller body size, black flagellum, tibiae and tarsi, elytra without pockets of setae and a finely punctate metaventrite. From E. bicolor Valentine, 1972 in North and Central America it differs by the smaller body size, brownish-black body, black antennae and legs, elytra without hair spots and the narrow pronotum and elytra.

Remarks. Both specimen no. C- 99 and the following no. C-112 belong to the tribe Eugonini based on the dorso-lateral sulciform antennal scrobes contiguous with the eyes and a cylindrical body with a basal transverse dorsal pronotal carina The lateral carina reaching the front margin of the pronotum is a feature of the genus Eugonus.

\section{Eugonus angustus sp. nov. Figure 4}

\section{zoobank.org/DEE06491-271B-4A81-8BF9-279712B8DC0B}

Holotype. Deposited in the PACO (accession \# C112).

Description. Length body, $6.3 \mathrm{~mm}$; length rostrum, $0.8 \mathrm{~mm}$. Body black with a covering of quite distinct, brownish, appressed setae. Rostrum wide and short, 0.5 times as long as pronotum, flat, without dorsal median carina; antennal scrobes almost sulciform, dorso-lateral, contiguous with eyes; forehead wide, convex, punctate; eyes large, almost rounded, distinctly convex, 1.2 times longer than wide; vertex weakly convex, densely punctate; temples quite long; antennae inserted at base of rostrum, quite long, not reaching middle of pronotum; antennal club not compact. Pronotum long bell-shaped; 1.7 times longer than wide at apex, 1.3 times longer than wide in middle, 1.6 times longer than wide at base, with complete lateral carina reaching front margin of pronotum; disk weakly convex, densely punctate; weakly transverse dorsal pronotal carina basal; scutellum trapezoidal. Elytra cylindrical, elongate and weakly convex, 2.5 times longer than wide at base and in middle, 3.1 times longer than wide at apical fourth, 1.9 times as long as pronotum, without clusters of setae; greatest width in middle; humeri weakly flattened; striae regular and distinct; strial punctures oval, dense; elytral intervals convex, wide, 3.0-4.0 times as wide as striae; apices of elytra not rounded; pygidium not concealed. Thorax punctate; precoxal portion of prosternum quite elongate, 1.9 times as long as procoxal cavities, 2.5 times as long as postcoxal portion; postcoxal portion 0.8 times as long as procoxal cavities; procoxal cavities narrowly separated; mesocoxal cavities widely separated; metaventrite densely punctate, metanepisternum narrow. Abdomen convex; first ventrite 1.1 times as long as length of metacoxal cavity; second ventrite 0.6 times as long as length of first ventrite; third ventrite 0.9 times as long as length of second ventrite; fourth ventrite equal in length to length of third ventrite; fifth ventrite 1.5 times as long as length of fourth ventrite. Legs long; pro- and mesocoxae round; metacoxae transverse; femora clavate, without teeth; trochanters obconical; profemora 3.4 times longer than wide; mesofemora 3.5 times longer than wide; metafemora 2.4 times longer than wide; tibiae flattened, almost straight; protibiae 6.0 times longer than wide in middle; mesotibiae 6.0 times longer than 

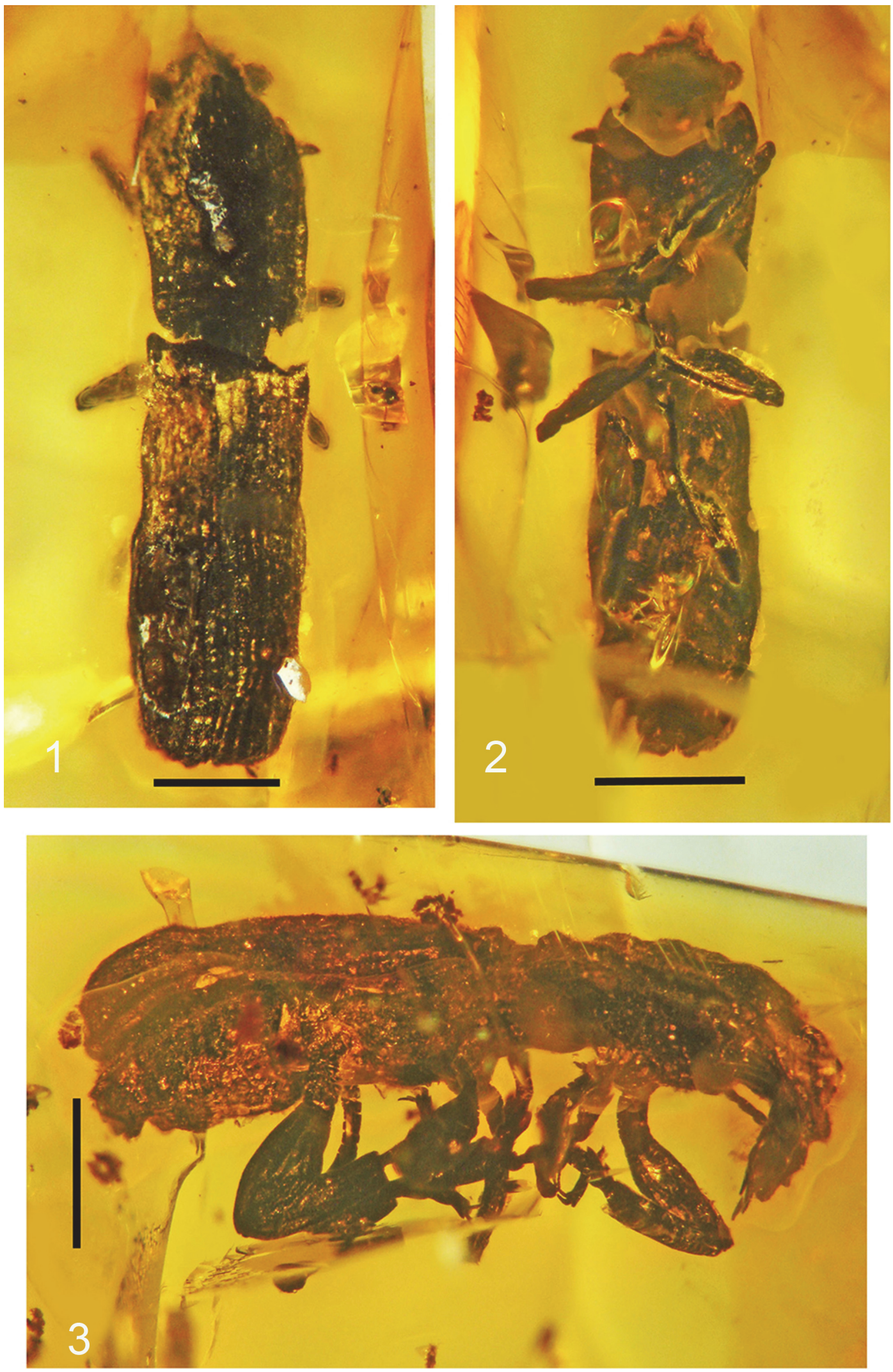

FIGURE 4. Holotype of Eugonus angustus sp. nov. PACO no. C-112 in Dominican amber. 1, dorsal view, scale bar equals $1.2 \mathrm{~mm}$; 2 , ventral view, scale bar equals $1.3 \mathrm{~mm}$; and $\mathbf{3}$, lateral view, scale bar equals $1.4 \mathrm{~mm}$. 
wide in middle; metatibiae 6.6 times longer than wide in middle; tarsi long, black; first to third tarsomeres conical; second tarsomere embracing third tarsomere laterally; fifth tarsomere elongate; tarsomeres with pulvilli on underside; tarsal claws free, large, distinct diverging, with basal teeth.

Type locality. Amber mine in the Cordillera Septentrional of the northern portion of the Dominican Republic.

Etymology. The specific epithet is taken from the Latin "angustus" equals narrow, in reference to the body form of the fossil.

Comparison. The new species is similar to $E$. subcylindricus Fahraeus, 1839 from Central and South America but differs by the small, and narrow body size, elongate elytra and pronotum, convex elytral intervals, stronger convex eyes and densely punctate metaventrite.

Tribe PIESOCORYNINI Valentine, 1960 Genus PIESOCORYNUS Dejean, 1834

Piesocorynus unibullus sp. nov.

Figure 5

zoobank.org/ABA40B18-FBAB-46A5-AECC-4409859372CB

Holotype. Probably female. Deposited in the PACO (accession \# C-83).

Description. Length body, $5.2 \mathrm{~mm}$; length rostrum, $1.0 \mathrm{~mm}$. Body brownish-black with a covering of distinct, dense, pale, appressed setae. Rostrum wide and short, equal in length and width, 0.5 times as long as pronotum, flattened, without dorsal median carina; antennal scrobes foveiform, lateral; forehead wide, flattened, punctate; eyes coarsely faceted, fewer than 26 rows of ommatidia perpendicular to long axis, not emarginate, large, weakly convex, 1.2 times longer than wide; vertex weakly convex, densely and finely punctate; temples short, 0.3 times as long as length of eye; antennae inserted in first third of rostrum, elongate, reaching pronotal transverse carina; first antennomere (scape) 2.3 times longer than wide; funicle with second to eighth elongate-conical antennomeres ; second antennomere 3.0 times longer than wide, 0.9 times as long as and 0.7 times as narrow as first antennomere; third to fifth antennomeres subequal in width; third antennomere 12.0 times longer than wide, 2.0 times as long as and 0.5 times as narrow as second antennomere; fourth antennomere 8.0 times longer than wide, 0.7 times as long as third antennomere; fifth antennomere equal in length to fourth antennomere; sixth antennomere 5.0 times longer than wide, 0.8 times as long as and 1.2 times as wide as fifth antennomere; seventh antennomere 4.2 times longer than wide, 0.8 times as long as and equal in width to sixth antennomere; eighth antennomere 1.3 times longer than wide, 0.8 times as long as and 2.5 times as wide as seventh antennomere; club not compact, 0.5 times
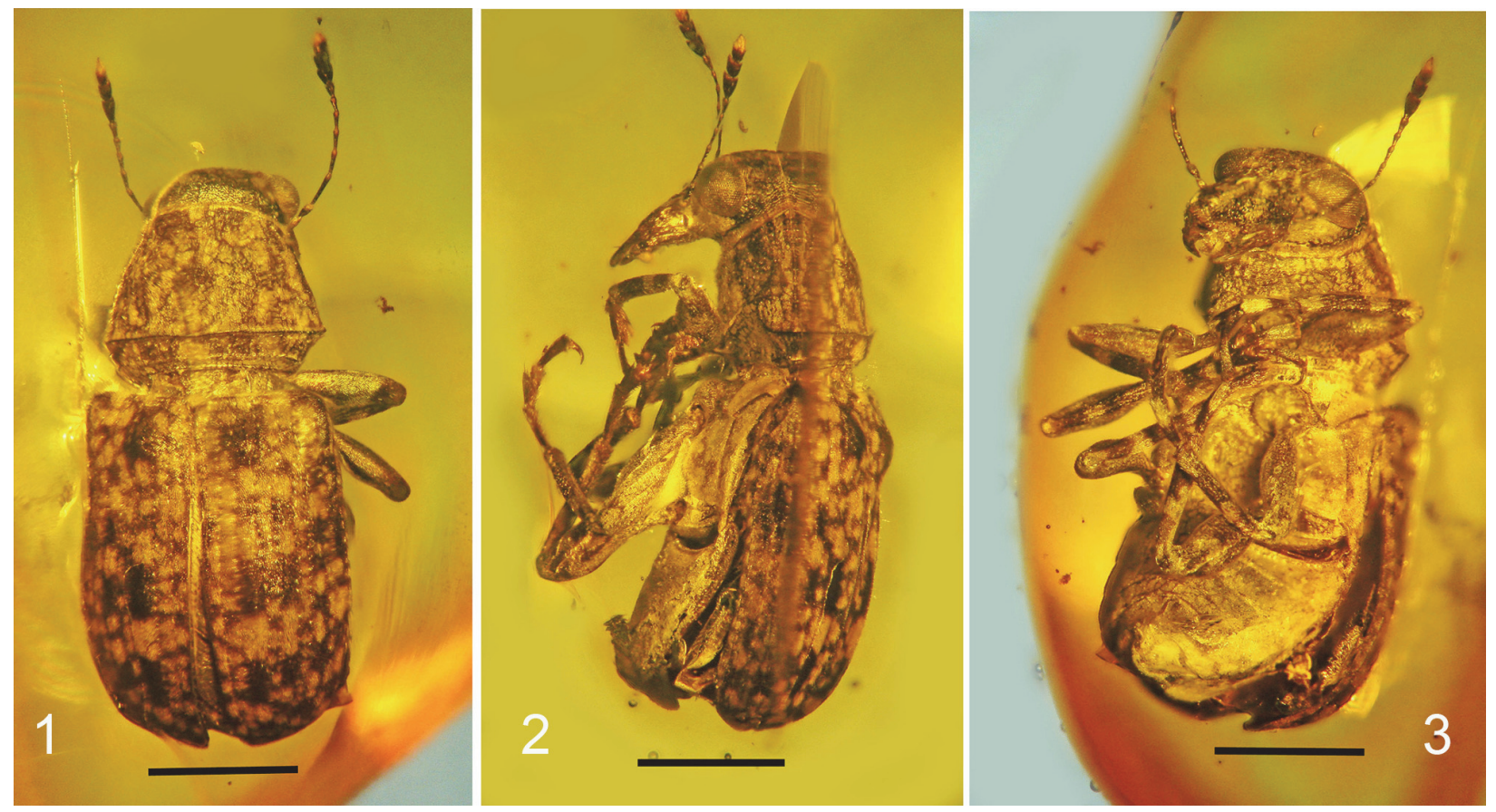

FIGURE 5. Holotype of Piesocorynus unibullus sp. nov. PACO no. C-83 in Dominican amber. 1, dorsal view, scale bar equals $1.3 \mathrm{~mm}$; 2 , lateral view, scale bar equals $1.3 \mathrm{~mm}$; and $\mathbf{3}$, ventral view, scale bar equals $1.2 \mathrm{~mm}$. 
as long as funicle; first antennomere of club 1.6 times longer than wide, 1.5 times as long as and 1.7 times as wide as eighth antennomere; second antennomere of club 1.4 times longer than wide, 0.9 times as long as and equal in width to first antennomere of club; third antennomere of club 3.0 times longer than wide, 1.3 times as long as and 0.6 times as narrow as second antennomere of club. Pronotum bell-shaped; 1.1 times longer than wide at apex, 0.8 times longer than wide in middle and 0.9 times longer than wide at base, with short lateral carinae; disk weakly flattened, densely and rugosely punctate, transverse dorsal pronotal carina antebasal; distance between transverse carina and base of pronotum 0.2 times as long as pronotum; scutellum trapezoidal. Elytra distinctly convex, 1.5 times longer than wide at base, 1.3 times longer than wide in middle, 1.5 times longer than wide at apical fourth, 2.2 times as long as pronotum; greatest width behind middle; elytron with one tubercle on base of second and third intervals; humeri weakly convex; striae regular and thin; strial punctures small, rounded, dense; elytral intervals flattened, wide, 3.3-6.0 times as wide as striae, sparsely and finely punctate; apices of elytra not rounded; pygidium not concealed. Thorax coarsely punctate; precoxal portion of prosternum elongate, 2.5 times as long as procoxal cavities, 5.0 times as long as postcoxal portion; postcoxal portion 0.5 times as long as procoxal cavities; procoxal cavities narrowly separated; mesocoxal cavities widely separated, metanepisternum narrow, 7.3 times longer than wide in middle. Abdomen convex; first ventrite 0.7 times as long as length of metacoxal cavities; second ventrite 1.1 times as long as length of first ventrite; third ventrite equal in length to second ventrite; fourth ventrite 0.8 times as long as length of third ventrite; fifth ventrite 1.1 times as long as length of fourth ventrite. Legs long; pro- and mesocoxae round; metacoxae transverse; femora clavate, without teeth; trochanters obconical; profemora 3.3 times longer than wide; mesofemora 3.0 times longer than wide; metafemora 3.1 times longer than wide; tibiae almost straight; mesotibiae 6.7 times longer than wide in middle; metatibiae 7.8 times longer than wide in middle; tarsi long; first to third tarsomeres conical; second tarsomere embracing third tarsomere laterally; fifth elongate; tarsomeres with pulvilli on underside; tarsal claws free, large, diverging, with basal teeth; metatarsi: first tarsomere 3.6 times longer than wide at base; second tarsomere 1.3 longer than wide at base, 0.6 times as long as and 1.6 times as wide as first tarsomere; third tar- somere equal in length and width, 0.6 times as long as and 0.8 times as wide as second tarsomere; fifth tarsomere 4.7 times longer than wide at base, 1.4 times as long as and 0.4 times as wide as second tarsomere.

Type locality. Amber mine in the Cordillera Septentrional of the northern portion of the Dominican Republic.

Etymology. The specific epithet is taken from the Latin "unis" equals one and the Latin "bullus" equals knob, in reference to the single tubercle on each elytron.

Remarks. The coarsely faceted eyes, fewer than 26 rows of ommatidia perpendicular to the long axis, antebasal pronotal transverse carina and eye margin not emarginate on the side nearest the antennal scrobes (also in PACO no. 83, 85, 86, 91, 101-105 and ISEA DA no. 2015/1) are features of the tribe Piesocorynini. These specimens (PACO no. $83,85,86,101-105$ and ISEA DA no. 2015/1) belong to the genus Piesocorynus based on the eyes with 15 or more rows of facets perpendicular to the maximum length and the third antennomere longer than either the second or fourth antennomeres.

\section{Piesocorynus bibullus sp. nov.} Figure 6

zoobank.org/95A49D80-A915-4845-B687-4B8F1E531603

Holotype. Probably female. Deposited in the ISEA DA no. 2015/1.

Description. Length body, $3.4 \mathrm{~mm}$; length rostrum, $0.5 \mathrm{~mm}$. Body black with covering of dark, dense, appressed setae. Rostrum quite wide, 0.5 times as long as pronotum, flattened, without dorsal median carina; antennal scrobes foveiform, lateral; forehead quite wide, flat, punctate; eyes oval, 1.5 times longer than wide, not emarginate, convex, coarsely faceted, fewer than 26 rows of ommatidia perpendicular to long axis; vertex weakly convex, punctate; temples 0.6 times as long as length of eye; antennae inserted in first third of rostrum, elongate, reaching humeri; first antennomere (scape) 1.8 times longer than wide; funicle with second to eighth antennomeres conical; second antennomere 1.5 times longer than wide, 0.9 times as long as and equal in width to first antennomere; third antennomere 2.7 times longer than wide, 1.3 times as long as and 0.8 times as narrow as second antennomere; fourth to sixth antennomeres subequal in width; fourth antennomere 2.8 times longer than wide, 0.9 times as long as and 0.8 times as narrow as third antennomere; fifth antennomere 2.4 times as wide as width as fourth antennomere; sixth antennomere equal to fifth antennomere; sev- 


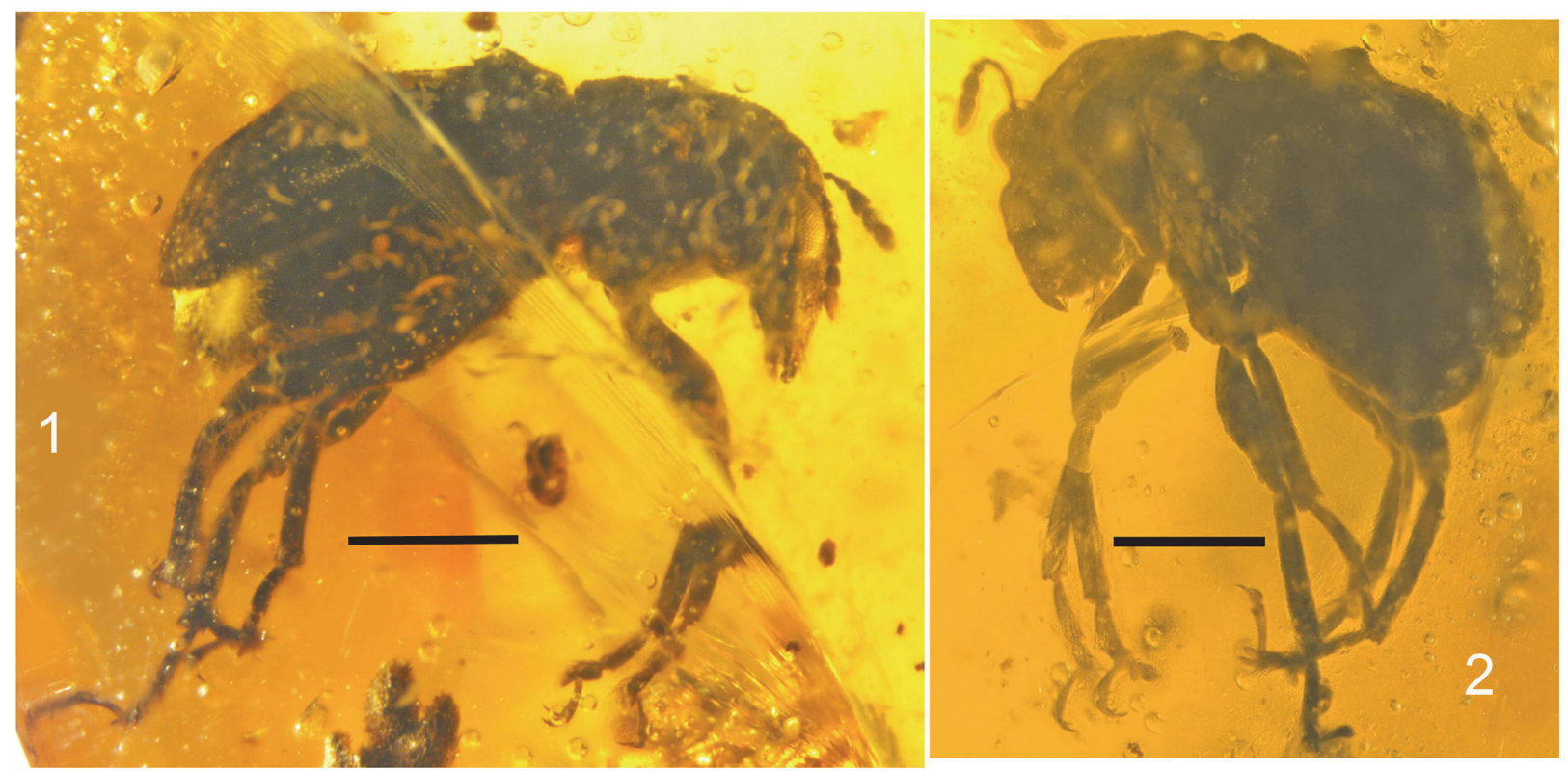

FIGURE 6. Holotype of Piesocorynus bibullus sp. nov. ISEA DA no. 2015/1 in Dominican amber. 1, dorsal-lateral view, scale bar equals $1.0 \mathrm{~mm}$; and 2, lateral view, scale bar equals $0.8 \mathrm{~mm}$.

enth antennomere 1.7 times longer than wide, 0.8 times as long as and 1.2 times as wide as sixth antennomere; eighth antennomere 2.0 times longer than wide, 1.2 times as long as and equal in width to seventh antennomere; club not compact, 0.5 times as long as funicle; first antennomere of club 1.3 times longer than wide, 1.3 times as long as and 2.0 times as wide as eighth antennomere; second antennomere of club 1.1 times longer than wide, 0.9 times as long as and 1.1 times as wide as first antennomere of club; third antennomere of club 1.7 times longer than wide, 1.4 times as long as and 0.9 times as narrow as second antennomere of club. Pronotum bell-shaped; with lateral carinae; disk weakly flattened, densely punctate, transverse dorsal pronotal carina antebasal; distance between transverse carina and base of pronotum 0.2 times as long as pronotum; scutellum trapezoidal. Elytra convex, 2.1 times as long as pronotum; greatest width behind middle; elytron with two tubercles on third interval: one at base and one in middle; humeri weakly convex; striae regular and narrow; strial punctures small, rounded, dense; elytral intervals weakly convex, quite wide, 1.5-2.7 times as wide as striae, sparsely and gentle punctate; apices of elytra not rounded; pygidium not concealed. Thorax punctate; precoxal portion of prosternum elongate, 1.1 times as long as procoxal cavities, 3.2 times as long as postcoxal portion; postcoxal portion 0.3 times as long as procoxal cavities; procoxal cavities narrowly separated; mesocoxal cavities widely separated, metanepisternum narrow, 6.7 times longer than wide in middle. Abdomen convex; first ventrite 0.4 times as long as length of metacoxal cavity; second ventrite 2.0 times as long as length of first ventrite; third ventrite subequal in length to second ventrite; fourth ventrite 0.5 times as long as length of third ventrite; fifth ventrite 1.2 times as long as length of fourth ventrite. Legs long; proand mesocoxae round; metacoxae transverse; femora clavate, without teeth; trochanters obconical; profemora 3.3 times longer than wide; mesofemora 2.8 times longer than wide; metafemora 2.9 times longer than wide; tibiae almost straight; mesotibiae 6.7 times longer than wide in middle; metatibiae 7.8 times longer than wide in middle; tarsi long; first to third tarsomeres conical; second tarsomere embracing third tarsomere laterally; fifth elongate; tarsomeres with pulvilli on underside; tarsal claws free, large, diverging, with basal teeth; protarsi: first tarsomere 2.8 times longer than wide at base; second tarsomere 1.4 longer than wide at base, 0.6 times as long as and 1.2 times as wide as first tarsomere; third tarsomere 0.8 times longer than wide, 0.6 times as long as and 0.9 times as wide as second tarsomere; fifth tarsomere 2.8 times longer than wide at base, 0.5 times as long as and 0.6 times as wide as second tarsomere; mesotarsi: first tarsomere 2.8 times lon- 
ger than wide at base; second tarsomere 1.7 longer than wide at base, 0.7 times as long as and 1.2 times as wide as first tarsomere; third tarsomere 1.2 times longer than wide, 0.6 times as long as and 0.8 times as wide as second tarsomere; fifth tarsomere 3.0 times longer than wide at base, 1.2 times as long as and 0.7 times as wide as second tarsomere; metatarsi: first tarsomere 3.4 times longer than wide at base; second tarsomere equal in length and width, 0.4 times as long as and 1.4 times as wide as first tarsomere; third tarsomere equal in length and width, 0.7 times as long as and 0.7 times as wide as second tarsomere; fifth tarsomere 4.3 times longer than wide at base, 2.4 times as long as and 0.6 times as wide as second tarsomere.

Type locality. Amber mine in the Cordillera Septentrional of the northern portion of the Dominican Republic.

Etymology. The specific epithet is taken from the Latin "bi" equals two and the Latin "bullus" equals knob, in reference to the two tubercles on each elytron.

\section{Piesocorynus tribullus sp. nov.} Figure 7

zoobank.org/2FF19DAA-D926-4427-B65F-CDA51CB48A8D

Holotype. Probably female. Deposited in the PACO (accession \# C-85).

Description. Length body, $5.9 \mathrm{~mm}$; length rostrum, $1.2 \mathrm{~mm}$. Body brownish-black with a covering of distinct, dense, pale, appressed setae. Rostrum wide and short, almost equal in length and width, 0.5 times as long as pronotum, flattened, without dorsal median carina; antennal scrobes foveiform, lateral; forehead wide, weakly convex, punctate; eyes coarsely faceted, fewer than 26 rows of ommatidia perpendicular to long axis, not emarginate, large, weakly convex, 1.3 times longer than wide; vertex weakly convex, densely punctate; temples short, 0.5 times as long as length of eye; antennae inserted in first third of rostrum, elongate, reaching pronotal transverse carina; funicle with second to eighth antennomeres elongate-conical; second antennomere 2.3 times longer than wide; third antennomere 4.5 times longer than wide, 1.4 times as long as and 0.7 times as narrow as second antennomere; fourth and fifth antennomeres subequal in width; fourth antennomere 3.0 times longer than wide, 0.6 times as long as and 0.9 times as narrow as third antennomere; fifth antennomere 4.0 times longer than wide, 1.3 times as long as fourth antennomere; sixth antennomere 3.9 times longer than wide, 0.9 times as long as and
0.9 times as wide as fifth antennomere; seventh antennomere 1.2 times longer than wide, 0.4 times as long as and 1.4 times as wide as sixth antennomere; eighth antennomere equal in length and width, subequal in length and 1.2 as wide as seventh antennomere; club not compact. Pronotum bell-shaped; 1.1 times longer than wide at apex, 0.8 times longer than wide in middle and 0.9 times longer than wide at base, with short lateral carinae; disk weakly flattened, densely and rugosely punctate; transverse dorsal pronotal carina antebasal; distance between transverse carina and base of pronotum 0.14 times as long as pronotum; scutellum trapezoidal. Elytra distinctly convex, 1.4 times longer than wide at base and in middle, 1.8 times longer than wide at apical fourth, 2.2 times as long as pronotum; greatest width behind middle; elytron with three tubercles: one tubercle on base of second and third intervals, one tubercle in middle and one tubercle before apex of third intervals; humeri convex; striae regular and thin; strial punctures small, rounded, dense; elytral intervals flattened, wide, 1.5-5.0 times as wide as striae, sparsely and faintly punctate; apices of elytra not rounded; pygidium not concealed. Thorax coarsely punctate; precoxal portion of prosternum elongate; postcoxal portion short; procoxal cavities narrowly separated; mesocoxal cavities widely separated, metanepisternum narrow, 7.4 times longer than wide in middle. Abdomen convex; second ventrite 0.9 times as long as length of first ventrite; third ventrite 0.8 times as long as length of second ventrite; fourth ventrite 0.8 times as long as length of third ventrite; fifth ventrite 1.4 times as long as length of fourth ventrite. Legs long; pro- and mesocoxae round; metacoxae transverse; femora clavate, without teeth; trochanters obconical; profemora 3.7 times longer than wide; mesofemora 4.1 times longer than wide; metafemora 3.5 times longer than wide; tibiae almost straight; mesotibiae 11.8 times longer than wide in middle; metatibiae 7.8 times longer than wide in middle; tarsi long; first to third tarsomeres conical; second tarsomere embracing third tarsomere laterally; fifth elongate; tarsomeres with pulvilli on underside; tarsal claws free, large, diverging, with basal teeth; mesotarsi: first tarsomere 3.0 times longer than wide at base; second tarsomere 1.3 longer than wide at base, 0.5 times as long as and 1.2 times as wide as first tarsomere; metatarsi: second tarsomere 0.7 times as long as first tarsomere; third tarsomere 0.4 times as long as second tarsomere; fifth tarsomere 3.0 times as long as second tarsomere. 

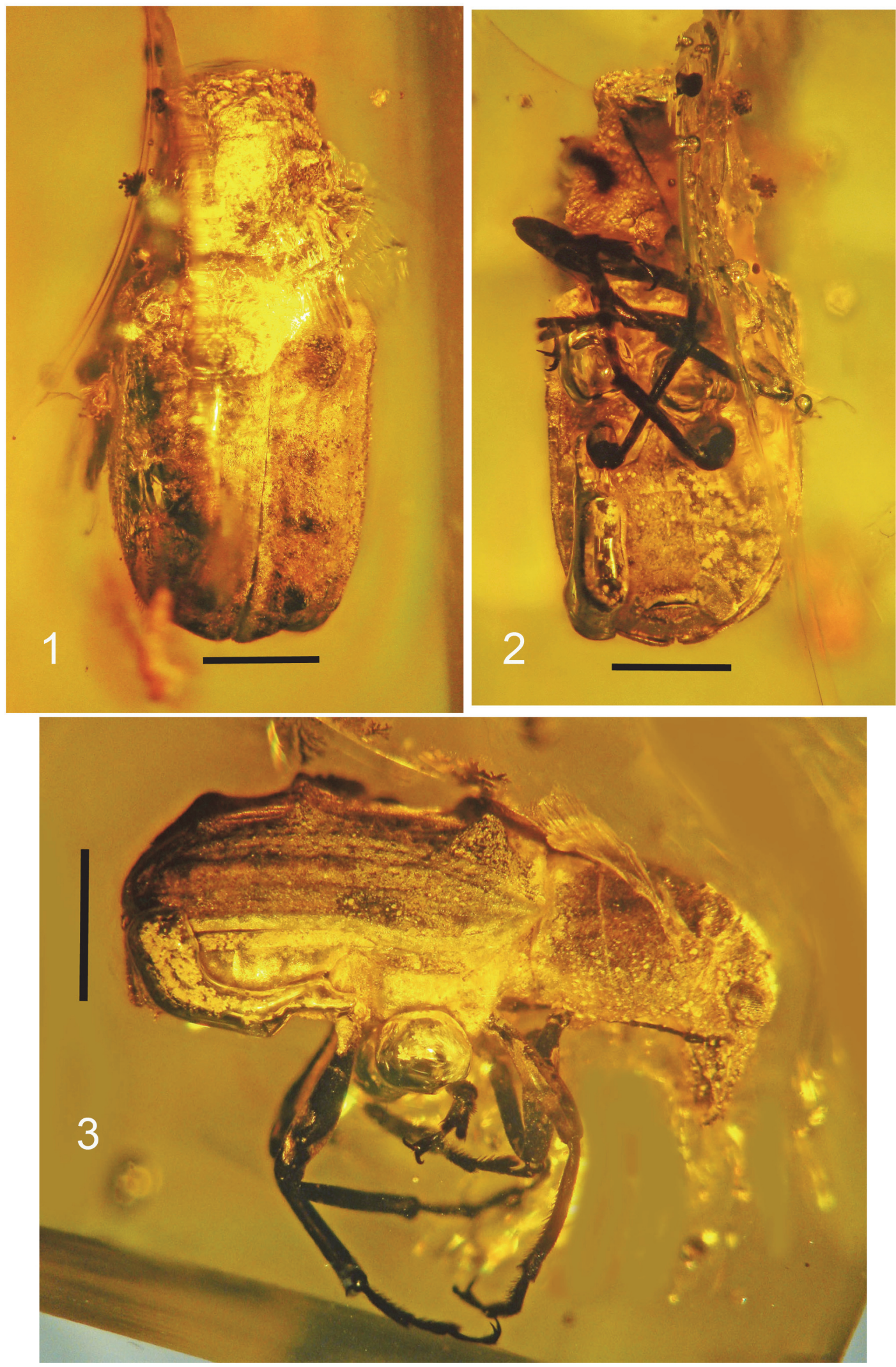

FIGURE 7. Holotype of Piesocorynus tribullus sp. nov. PACO no. C-85 in Dominican amber. 1, dorsal view, scale bar equals $1.1 \mathrm{~mm}$; 2, ventral view, scale bar equals $1.2 \mathrm{~mm}$; and $\mathbf{3}$, lateral view, scale bar equals $1.3 \mathrm{~mm}$. 
Type locality. Amber mine in the Cordillera Septentrional of the northern portion of the Dominican Republic.

Etymology. The specific epithet is taken from the Latin "tri" equals three and the Latin "bullus" equals knob, in reference to the three tubercles on each elytron.

\section{Piesocorynus brevitectus sp. nov. Figure 8}

zoobank.org/3B32B2BF-6972-49AB-B025-D76F9EB60B4F

Holotype. Probably male. Deposited in the PACO (accession \# C-101).

Description. Length body, $4.6 \mathrm{~mm}$; length rostrum, $1.1 \mathrm{~mm}$. Body black with covering of distinct, dense, pale, appressed setae; thorax and abdomen brown. Rostrum wide, 0.8 times longer than wide in middle, 0.5 times as long as pronotum, flattened, without dorsal median carina, densely punctate; antennal scrobes foveiform, lateral; forehead wide, flattened, punctate; eyes rounded, coarsely faceted, fewer than 26 rows of ommatidia perpendicular to long axis, not emarginate, convex, 1.5 times longer than wide; vertex weakly convex, densely punctate; temples short, 0.3 times as long as length of eye; antennae inserted in first third of rostrum, elongate, extending beyond humeri and reaching first third of elytra; funicle with second to eighth antennomeres elongate-conical; second antennomere 2.5 times longer than wide; third antennomere 4.7 times longer than wide, 1.4 times as long as and 0.8 times as narrow as second antennomere; fourth antennomere 3.5 times longer than wide, equal in length and 1.3 times as wide as third antennomere; fifth antennomere 3.0 times longer than wide, 0.9 times as long as and equal in width to fourth antennomere; sixth antennomere 3.0 times longer than wide, 0.8 times as long as and 0.8 times as wide as fifth antennomere; seventh antennomere 2.5 times longer than wide, 1.1 times as long as and 1.3 times as wide as sixth antennomere; eighth antennomere 1.3 times longer than wide, 0.9 times as long as and 1.8 times as wide as seventh antennomere; club not compact, long, 0.5 times as long as funicle; first antennomere of club 1.2 times longer than wide, 1.7 times as long as and 1.9 times as wide as eighth antennomere; second antennomere of club 0.8 times longer than wide, 0.7 times as long as and 1.1 times as wide as first antennomere of club; third antennomere of club 1.6 times longer than wide, 1.2 times as long as and 0.6 times as narrow as second antennomere of club. Pronotum bellshaped; 1.4 times longer than wide at apex, 0.9 times longer than wide in middle and at base, with quite long lateral carinae; disk flattened, densely punctate, transverse dorsal pronotal carina antebasal; distance between transverse carina and base of pronotum 0.08 times as long as pronotum; its sides evenly rounded; scutellum trapezoidal. Elytra convex, 1.2 times longer than wide at base and in middle, 1.4 times longer than wide at apical fourth, 1.5 times as long as pronotum; greatest width behind middle; elytron without tubercles; humeri weakly flattened; striae regular and thin; strial punctures rounded, dense; elytral intervals weakly convex; apices of elytra not rounded; pygidium not concealed. Thorax punctate; precoxal portion of prosternum elongate, postcoxal portion short; procoxal cavities narrowly separated; mesocoxal cavities widely separated, metanepisternum quite wide, 4.9 times longer than wide in middle. Abdomen convex; first ventrite equal in length to length of metacoxal cavity; second ventrite 0.9 times as long as length of first ventrite; third ventrite 0.8 times as long as length of second ventrite; fourth ventrite 1.4 times as long as length of third ventrite; fifth ventrite 1.2 times as long as length of fourth ventrite. Legs long; pro- and mesocoxae round; metacoxae transverse; femora clavate, without teeth; trochanters obconical; metafemora 2.5 times longer than wide; tibiae almost straight; metatibiae 5.4 times longer than wide in middle; tarsi long; first to third tarsomeres conical; second tarsomere embracing third tarsomere laterally; fifth elongate; tarsomeres with pulvilli on underside; tarsal claws free, large, diverging, with basal teeth.

Type locality. Amber mine in Chiapas Highlands of the Simojovel area in Chiapas, Mexico.

Etymology. The specific epithet is taken from the Latin "brevis" equals short and the Latin "tego" equals cover in reference to the short elytra.

\section{Piesocorynus hamus sp. nov.} Figure 9

zoobank.org/B35DFFBF-D73D-432B-8409-8AA082F6AB4A

Holotype. Probably female. Deposited in the PACO (accession \# C-86).

Description. Length body, $4.3 \mathrm{~mm}$; length rostrum, $0.4 \mathrm{~mm}$. Body brown with covering of distinct, dense, pale, appressed setae. Rostrum wide, 0.5 times as long as pronotum, flattened, without dorsal median carina, punctate; antennal scrobes foveiform, lateral; forehead wide, punctate; eyes coarsely faceted, fewer than 26 rows of ommatidia perpendicular to long axis, not emarginate, convex; temples short; antennae inserted in first third of rostrum, elongate, extending beyond humeri and reaching first third of elytra; funicle with second to eighth antennomeres elongate-conical; third anten- 

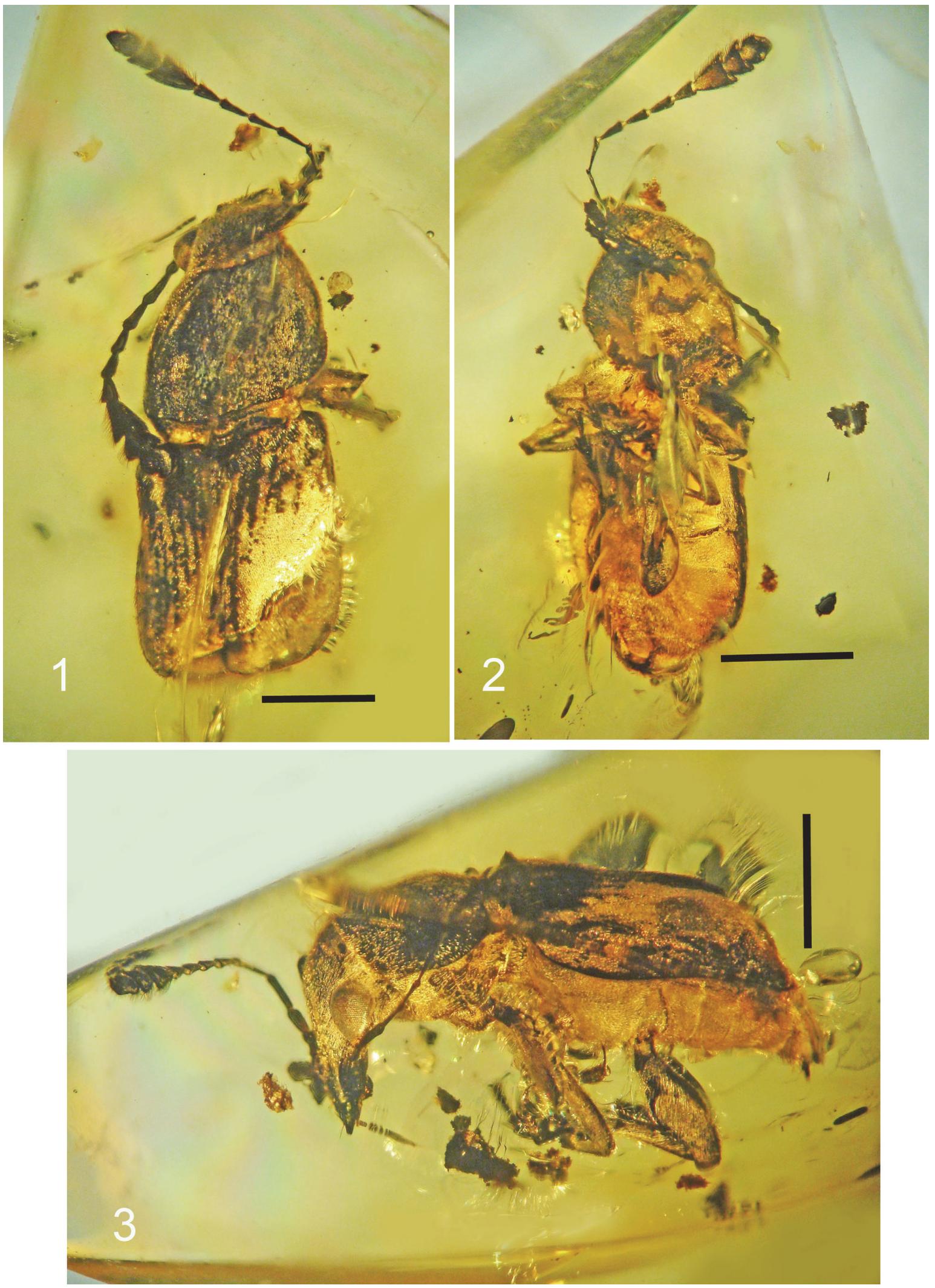

FIGURE 8. Holotype of Piesocorynus brevitectus sp. nov. PACO no. C-101 in Mexican amber. 1, dorsal view, scale bar equals $1.1 \mathrm{~mm} ; \mathbf{2}$, ventral view, scale bar equals $1.3 \mathrm{~mm} ; \mathbf{3}$, and lateral view, scale bar equals $1.2 \mathrm{~mm}$. 


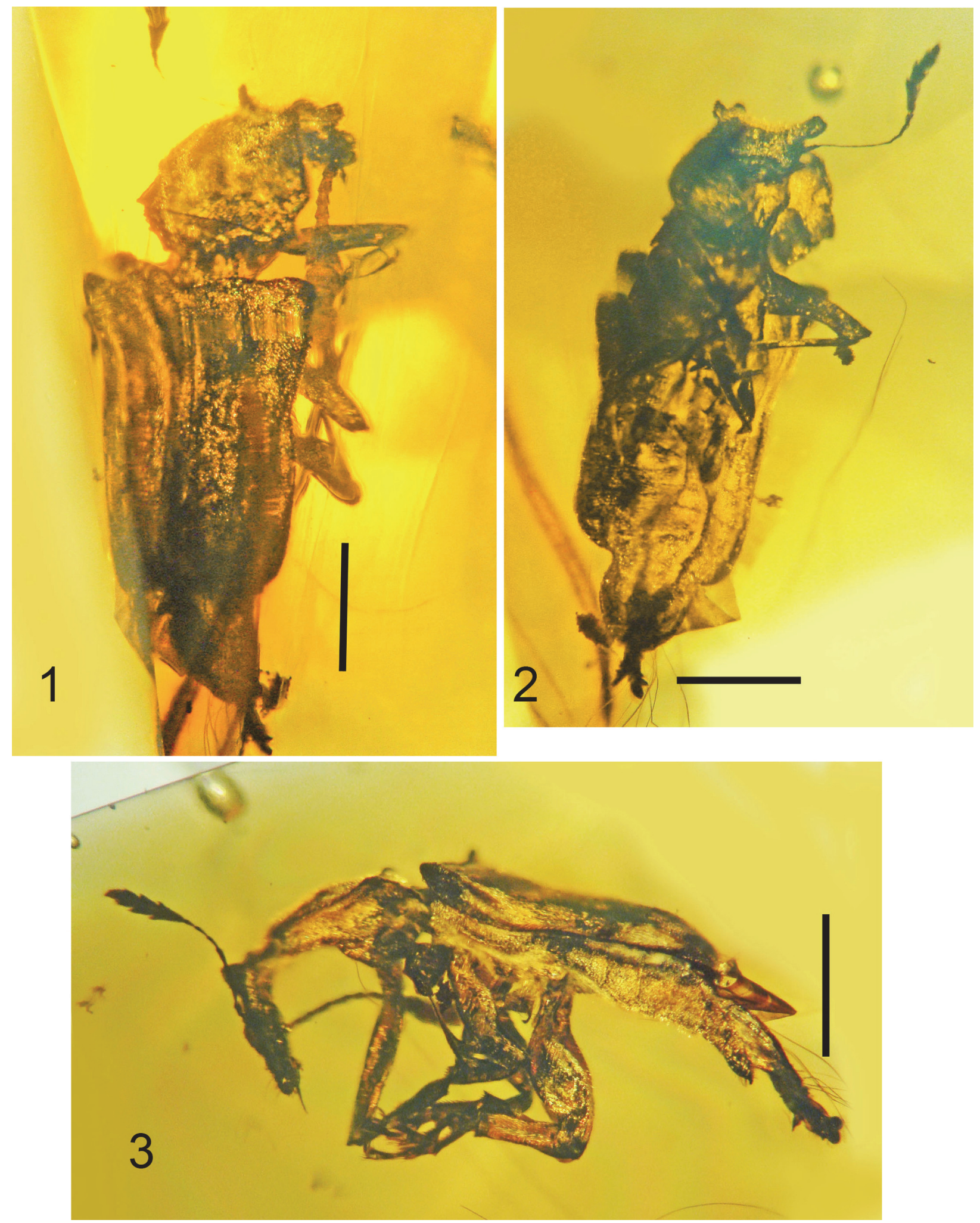

FIGURE 9. Holotype of Piesocorynus hamus sp. nov. PACO no. C-86 in Dominican amber. 1, dorsal view, scale bar equals $1.1 \mathrm{~mm}$; 2, ventral view, scale bar equals $1.0 \mathrm{~mm}$; and 3, lateral view, scale bar equals $1.1 \mathrm{~mm}$. 
nomere 2.3 times longer than wide; fourth antennomere 1.8 times longer than wide, equal in length and 1.3 times as wide as third antennomere; fifth antennomere equal in length and width, 0.6 times as long as and 1.1 times as wide as fourth antennomere; sixth antennomere 0.9 times longer than wide, equal in length and 1.1 times as wide as fifth antennomere; seventh antennomere subequal to sixth antennomere; eighth antennomere 0.7 times longer than wide, 1.1 times as long as and 1.4 times as wide as seventh antennomere; club not compact, wide; first antennomere of club 0.8 times longer than wide, 2.2 times as long as and 1.9 times as wide as eighth antennomere; second antennomere of club 0.8 times longer than wide, 0.9 times as long as and equal in width to first antennomere of club; third antennomere of club 1.4 times longer than wide, 1.5 times as long as and 0.8 times as narrow as second antennomere of club. Pronotum bell-shaped; 2.3 times longer than wide at apex, 1.1 times longer than wide in middle and 1.2 times longer than wide at base, with quite long lateral carinae; disk flattened, densely punctate, transverse dorsal pronotal carina antebasal; distance between transverse carina and base of pronotum 0.17 times as long as pronotum; its sides angular in middle; scutellum trapezoidal. Elytra flattened, 1.4 times longer than wide at base, 1.7 times longer than wide in middle, 1.8 times longer than wide at apical fourth, 2.1 times as long as pronotum; greatest width in humeri and behind middle; elytron without tubercles; humeri convex; striae regular and thin; strial punctures rounded, dense; elytral intervals weakly convex; apices of elytra not rounded; pygidium not concealed. Thorax punctate; precoxal portion of prosternum elongate, 2.5 times as long as procoxal cavities length, 3.1 times as long as postcoxal portion, postcoxal portion quite short, 0.8 times as long as length of procoxal cavity; procoxal cavities narrowly separated; mesocoxal cavities widely separated, metanepisternum narrow, 5.5 times longer than wide in middle. Abdomen weakly convex; first ventrite 1.2 times as long as length of metacoxal cavity; second and third ventrites subequal in length to first ventrite; fourth ventrite 0.9 times as long as length of third ventrite; fifth ventrite 1.1 times as long as length of fourth ventrite. Legs long; pro- and mesocoxae round; metacoxae transverse; femora clavate, without teeth; trochanters obconical; metafemora 2.7 times longer than wide; tibiae almost straight; metatibiae 4.4 times longer than wide in middle; tarsi long; first to third tarsomeres conical; second tarsomere embracing third tarsomere laterally; fifth elongate; tarsomeres with pulvilli on underside; tarsal claws free, large, diverging, with basal teeth.

Type locality. Amber mine in the Cordillera Septentrional of the northern portion of the Dominican Republic.

Etymology. The specific epithet is taken from the Latin "hamus" equals angle, in reference to the sharp angle on the lateral margins of the pronotum.

\section{Piesocorynus elongatus sp. nov.} Figure 10

zoobank.org/DE715D93-A22A-4291-8996-7968946EAB1E

Holotype. Probably female. Deposited in the PACO (accession \# C-102).

Description. Length body, $4.1 \mathrm{~mm}$; length rostrum, $1.1 \mathrm{~mm}$. Body brown with covering of distinct, dense, pale, appressed setae. Rostrum wide, 0.7 times as long as pronotum, flattened, without dorsal median carina, punctate; antennal scrobes foveiform, lateral; forehead wide; eyes coarsely faceted, fewer than 26 rows of ommatidia perpendicular to long axis, convex; temples short; antennae inserted in first third of rostrum, elongate, not reaching humeri; antennomeres elongate-conical; second antennomere 2.0 times longer than wide; second-fourth antennomeres subequal in length; third antennomere 2.7 times longer than wide, 0.8 times as narrow as second antennomere; fourth antennomere 3.2 times longer than wide, 0.8 times as narrow as third antennomere; fifth antennomere 2.0 times longer than wide, 0.8 times as long as and 1.2 times as wide as fourth antennomere; sixth antennomere 1.7 times longer than wide, 0.8 times as long as fifth antennomere; sixth-eighth antennomeres subequal in length; seventh antennomere 1.3 times longer than wide, 1.3 times as wide as sixth antennomere; eighth antennomere equal in length and width, 1.3 times as wide as seventh antennomere; club not compact, wide; first antennomere of club 1.1 times longer than wide, 1.8 times as long as and 1.6 times as wide as eighth antennomere; second antennomere of club 0.8 times longer than wide, 0.9 times as long as and 1.1 times as wide as first antennomere of club; third antennomere of club 1.1 times longer than wide, equal in length and 0.8 times as narrow as second antennomere of club. Pronotum elongate, bell-shaped; 1.4 times longer than wide at apex, 1.2 times longer than wide in middle and 1.1 times longer than wide at base, with quite long lateral carinae; disk flattened, densely punctate, transverse dorsal pronotal carina antebasal; distance between transverse carina and base of pronotum 0.08 times as long as pronotum; its sides almost straight; scutellum trapezoidal. Elytra flattened, 1.3 

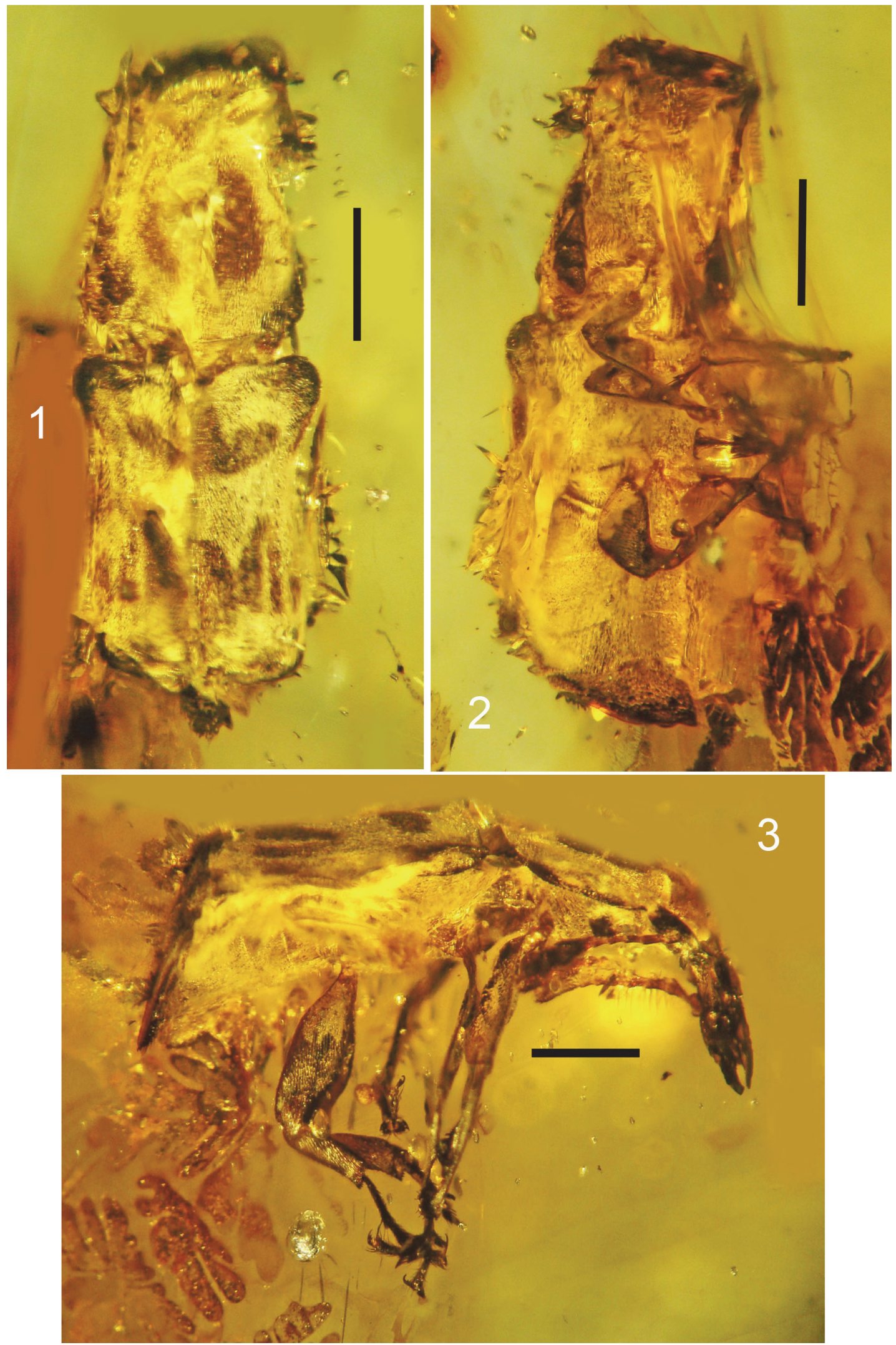

FIGURE 10. Holotype of Piesocorynus elongatus sp. nov. PACO no. C-102 in Mexican amber. 1, dorsal view, scale bar equals $1.0 \mathrm{~mm}$; 2, ventral view, scale bar equals $0.8 \mathrm{~mm}$; and 3, lateral view, scale bar equals $0.8 \mathrm{~mm}$. 
times longer than wide at base, 1.4 times longer than wide in middle, 1.6 times longer than wide at apical fourth, 1.4 times as long as pronotum; greatest width in humeri and behind middle; elytron without tubercles; humeri distinctly convex; striae regular and thin; strial punctures rounded, dense; elytral intervals weakly convex; apices of elytra not rounded; pygidium not concealed. Thorax densely punctate; precoxal portion of prosternum elongate, postcoxal portion short; procoxal cavities narrowly separated; mesocoxal cavities widely separated, metanepisternum narrow. Abdomen weakly convex; first ventrite 0.9 times as long as length of metacoxal cavities; second ventrite 1.3 times as long as length of first ventrite; third ventrite 0.9 times as long as length of second ventrite; fourth ventrite 0.9 times as long as length of third ventrite; fifth ventrite 1.1 times as long as length of fourth ventrite. Legs long; pro- and mesocoxae round; metacoxae transverse; femora clavate, without teeth; trochanters obconical; profemora 3.0 times longer than wide; metafemora 3.2 times longer than wide; tibiae almost straight; protibiae 6.7 times longer than wide in middle; metatibiae 7.5 times longer than wide in middle; tarsi long; first to third tarsomeres conical; second tarsomere embracing third tarsomere laterally; fifth tarsomere elongate; tarsomeres with pulvilli on underside; tarsal claws free, large, diverging, with basal teeth; metatarsi: first tarsomere 5.4 times longer than wide at base; second tarsomere 1.3 longer than wide at base, 0.4 times as long as and 1.7 times as wide as first tarsomere.

Type locality. Amber mine in Chiapas Highlands of the Simojovel area in Chiapas, Mexico.

Etymology. The specific epithet is taken from the Latin "elongatus" equals prolonged, in reference to the body shape.

\section{Piesocorynus parategus sp. nov.} Figure 11

\section{zoobank.org/BC03952A-E1DA-43B2-9FE2-66A97E2EEBB7}

Holotype. Probably female. Deposited in the PACO (accession \# C-103).

Description. Length body, $3.9 \mathrm{~mm}$; length rostrum, $0.9 \mathrm{~mm}$. Body brown with covering of distinct, dense, pale, appressed setae. Rostrum wide and short, equal in length and width, 0.4 times as long as pronotum, flattened, without dorsal median carina; antennal scrobes foveiform, lateral; forehead wide, flattened, punctate; eyes coarsely faceted, fewer than 26 rows perpendicular to long axis, not emarginate, large, convex, round, vertex weakly convex, densely and finely punctate; temples quite short, 0.4 times as long as length of eye; antennae inserted in first third of rostrum, elongate, not reaching humeri; first antennomere (scape) 2.0 times longer than wide; funicle with second to eighth antennomeres elongate-conical; second antennomere 3.5 times longer than wide, 1.4 times as long as and 0.8 times as narrow as first antennomere; second and third antennomeres subequal in width; third antennomere 4.0 times longer than wide, 1.1 times as long as second antennomere; third and fourth antennomeres equal in length; fourth antennomere 5.3 times longer than wide, 0.8 times as long as third antennomere; fifth antennomere 4.7 times longer than wide, 0.9 times as long as fourth antennomere; sixth antennomere 3.0 times longer than wide, 0.9 times as long as and 1.3 times as wide as fifth antennomere; seventh antennomere 1.8 times longer than wide, 0.9 times as long as and 1.5 times as wide as sixth antennomere; eighth antennomere 1.3 times longer than wide, 0.9 times as long as and 1.3 times as wide as seventh antennomere; club not compact, 0.9 times as long as funicle; first antennomere of club equal in length and width, 2.8 times as long as and 3.5 times as wide as eighth antennomere; second antennomere of club 0.8 times longer than wide, 1.3 times as long as and 0.9 times as narrow as first antennomere of club; third antennomere of club 1.5 times longer than wide, 1.5 times as long as and 0.8 times as narrow as second antennomere of club. Pronotum wide-bell-shaped; 0.9 times longer than wide at apex, 0.7 times longer than wide in middle and 0.8 times longer than wide at base, with long lateral carinae; disk weakly flattened, densely punctate, transverse dorsal pronotal carina antebasal; distance between transverse carina and base of pronotum 0.16 times as long as pronotum; scutellum trapezoidal. Elytra distinctly convex, 1.1 times longer than wide at base, 1.0 times longer than wide in middle, 1.3 times longer than wide at apical fourth, 2.1 times as long as pronotum; greatest width behind middle; elytron without tubercles; humeri weakly convex; striae regular and thin; strial punctures rounded and dense; elytral intervals flattened, narrow, 0.9-1.1 times as wide as striae, sparsely and faintly punctate; apices of elytra not rounded; pygidium not concealed. Thorax coarsely punctate; precoxal portion of prosternum elongate, 1.3 times as long as procoxal cavities, 1.6 times as long as postcoxal portion; postcoxal portion 0.8 times as long as procoxal cavities; procoxal cavities narrowly separated; mesocoxal cavities widely separated, metanepisternum wide, 3.0 times longer than wide in middle. Abdomen convex; first ventrite 1.2 times as long as 

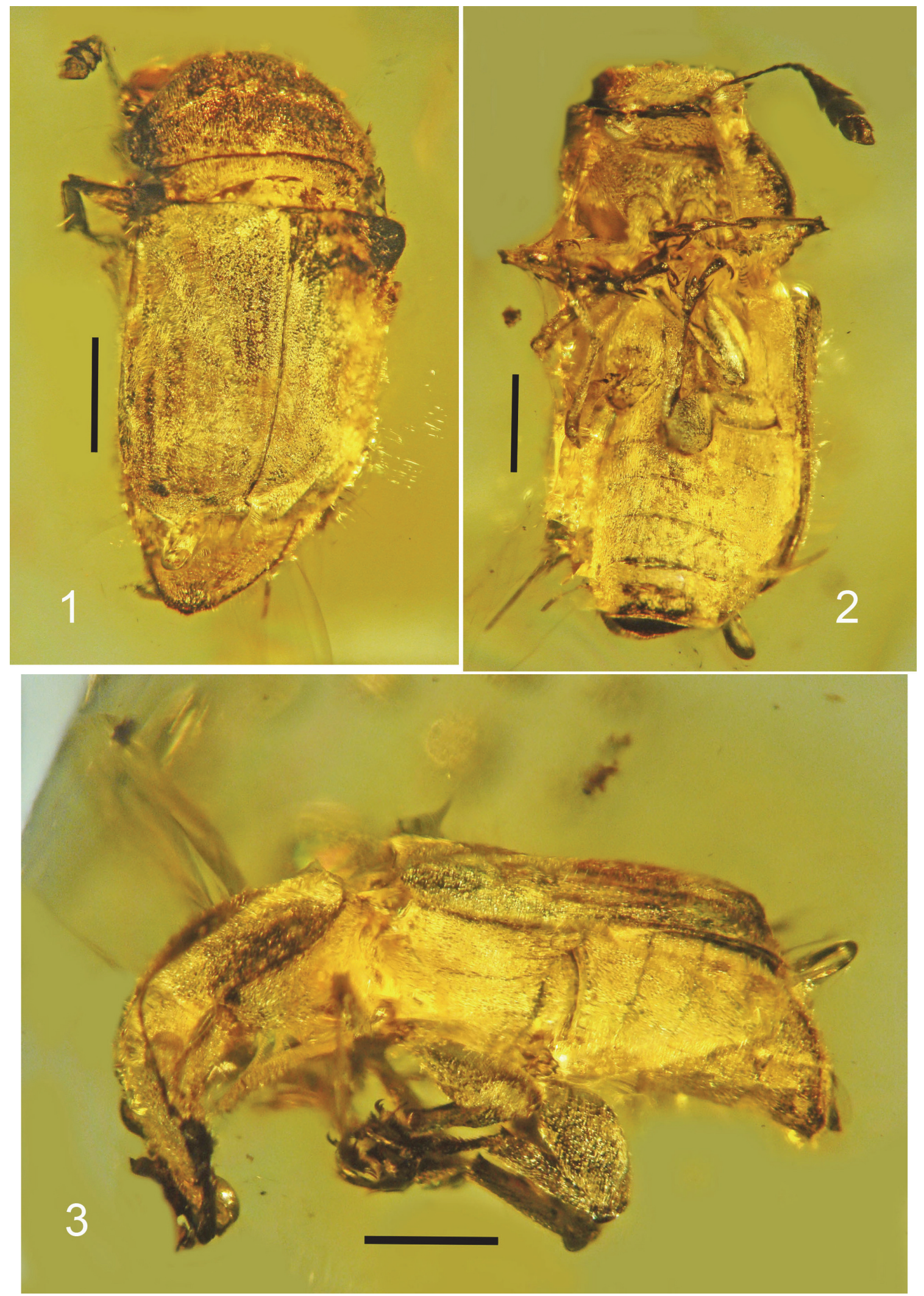

FIGURE 11. Holotype of Piesocorynus parategus sp. nov. PACO no. C-103 in Mexican amber. 1, dorsal view, scale bar equals $0.8 \mathrm{~mm} ; 2$, ventral view, scale bar equals $0.7 \mathrm{~mm}$; and $\mathbf{3}$, lateral view, scale bar equals $0.7 \mathrm{~mm}$. 
length of metacoxal cavity; second ventrite 0.9 times as long as length of first ventrite; third ventrite equal in length to length of second ventrite; fourth ventrite 0.9 times as long as length of third ventrite; fifth ventrite 1.2 times as long as length of fourth ventrite. Legs long; pro- and mesocoxae round; metacoxae transverse; femora clavate, without teeth; trochanters obconical; metafemora 2.2 times longer than wide; tibiae almost straight; metatibiae 5.1 times longer than wide in middle; tarsi long; first to third tarsomeres conical; second tarsomere embracing third tarsomere laterally; fifth elongate; tarsomeres with pulvilli on underside; tarsal claws free, large, diverging, with basal teeth; protarsi: first tarsomere 3.3 times longer than wide at base; second tarsomere 1.2 longer than wide at base, 0.9 times as long as and 2.4 times as wide as first tarsomere; third tarsomere equal in length and width, 0.4 times as long as and 0.5 times as wide as second tarsomere; fifth tarsomere 3.8 times longer than wide at base, 1.1 times as long as and 0.8 times as wide as second tarsomere; metatarsi: first tarsomere 4.6 times longer than wide at base; second tarsomere 1.6 times longer than wide at base, 1.1 times as long as and 3.1 times as wide as first tarsomere; third tarsomere equal in length and width, 0.4 times as long as and 0.7 times as wide as second tarsomere; fifth tarsomere 5.3 times longer than wide at base, 0.9 times as long as and 0.3 times as wide as second tarsomere.

Type locality. Amber mine in Chiapas Highlands of the Simojovel area in Chiapas, Mexico.

Etymology. The specific epithet is taken from the Latin "parus" equals equal, and the Latin "tego" equals cover, indicating that the length and width of the elytra are approximately of equal values.

Piesocorynus villosus sp. nov. Figure 12

zoobank.org/0CDC77A2-1283-4175-8BB0-4B80A326CE9B

Holotype. Probably female. Deposited in the PACO (accession \# C-104).

Description. Length body, $4.8 \mathrm{~mm}$; length rostrum, $0.5 \mathrm{~mm}$. Body brown with covering of distinct, dense, pale, appressed setae. Rostrum short, 1.1 times longer than wide at apex, 0.9 times longer than wide in middle, 1.1 times longer than wide at base, 0.7 times as long as pronotum, flattened, without dorsal median carina, densely punctate; antennal scrobes foveiform, lateral; forehead wide, 0.8 times as narrow as rostrum base width, flattened, punctate; eyes coarsely faceted, fewer than 26 rows of ommatidia perpendicular to long axis, not emarginate, large, convex, round, vertex weakly convex, densely punctate; temples short; antennae inserted in first third of rostrum, elongate, reaching humeri; funicle with second to eighth antennomeres elongate-conical; second antennomere 5.0 times longer than wide; third antennomere 4.1 times longer than wide, 0.9 times as long as and 1.1 times as wide as second antennomere; second and third antennomeres equal in width; fourth antennomere 2.7 times longer than wide, 0.7 times as long as third antennomere; fifth antennomere 2.3 times longer than wide, 1.2 times as long as and 1.4 times as wide as fourth antennomere; fifth and sixth antennomeres equal in width; sixth antennomere 3.0 times longer than wide, 1.3 times as long as fifth antennomere; seventh antennomere 3.2 times longer than wide, 0.9 times as long as and 0.8 times as wide as sixth antennomere; eighth antennomere 2.3 times longer than wide, 0.9 times as long as and 1.2 times as wide as seventh antennomere; club not compact, 0.4 times as long as funicle; first antennomere of club 1.2 times longer than wide, equal in length and 2.0 times as wide as eighth antennomere; second antennomere of club equal in length and width, equal in length and 1.2 times as narrow as first antennomere of club; third antennomere of club 1.7 times longer than wide, 1.4 times as long as and 0.9 times as narrow as second antennomere of club. Pronotum bell-shaped; 1.8 times longer than wide at apex, 1.0 times longer than wide in middle and 1.1 times longer than wide at base, with long lateral carinae; disk weakly flattened, densely punctate, transverse dorsal pronotal carina antebasal; distance between transverse carina and base of pronotum 0.15 times as long as pronotum; scutellum trapezoidal. Elytra weakly flattened, 1.4 times longer than wide at base and in middle, 1.3 times longer than wide at apical fourth, 1.9 times as long as pronotum; greatest width at humeri and behind middle; elytron without tubercle; humeri convex; striae regular and thin; strial punctures rounded and dense; elytral intervals flattened, quite wide, 2.0-3.3 times as wide as points in striae, weakly punctate; apices of elytra not rounded; pygidium not concealed. Thorax coarsely punctate; precoxal portion of prosternum elongate; postcoxal portion short; procoxal cavities narrowly separated; mesocoxal cavities widely separated, metanepisternum narrow. Abdomen convex; first ventrite 1.1 times as long as length of metacoxal cavity; second ventrite 0.8 times as long as length of first ventrite; third ventrite 1.1 times as long as length of second ventrite; fourth ventrite 1.2 times as long as length of third ventrite; fifth ventrite 1.4 times as long as length of 

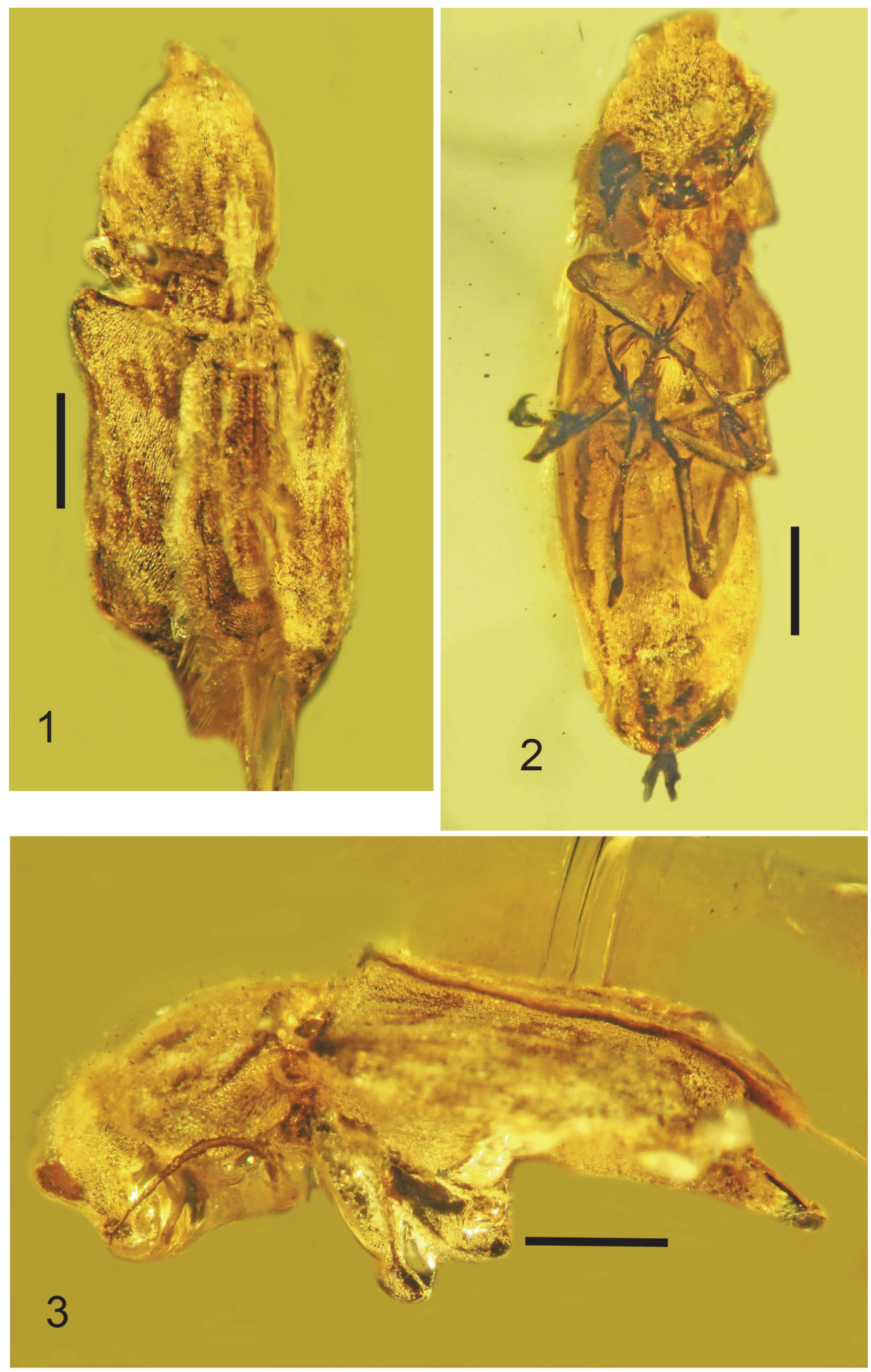

FIGURE 12. Holotype of Piesocorynus villosus sp. nov. PACO no. C-104 in Mexican amber. 1, dorsal view, scale bar equals $0.9 \mathrm{~mm}$; 2 , ventral view, scale bar equals $0.7 \mathrm{~mm}$; and 3 , lateral view, scale bar equals $0.9 \mathrm{~mm}$. 
fourth ventrite. Legs long; pro- and mesocoxae round; metacoxae transverse; femora clavate, without teeth; trochanters obconical; tibiae almost straight; protibiae 8.8 times longer than wide in middle; metatibiae 10.8 times longer than wide in middle; tarsi long; first to third tarsomeres conical; second tarsomere embracing third tarsomere laterally; fifth elongate; tarsomeres with pulvilli on underside; tarsal claws free, large, diverging, with basal teeth; protarsi: first tarsomere 2.4 times longer than wide at base; second tarsomere 1.4 longer than wide at base, 1.4 times as long as and 2.4 times as wide as first tarsomere; third tarsomere equal in length and width, 0.3 times as long as and 0.4 times as wide as second tarsomere; fifth tarsomere 5.0 times longer than wide at base, 0.8 times as long as and 0.3 times as wide as second tarsomere; mesotarsi: first tarsomere 3.0 times longer than wide at base; second tarsomere 1.4 longer than wide at base, 0.8 times as long as and 1.8 times as wide as first tarsomere; third tarsomere equal in length and width, 0.6 times as long as and 0.8 times as wide as second tarsomere; fifth tarsomere 5.0 times longer than wide at base, 1.5 times as long as and 0.4 times as wide as second tarsomere; metatarsi: first tarsomere 3.7 times longer than wide at base; second tarsomere 1.4 longer than wide at base, 0.8 times as long as and 2.0 times as wide as first tarsomere; third tarsomere equal in length and width.

Type locality. Amber mine in Chiapas Highlands of the Simojovel area in Chiapas, Mexico.

Etymology. The specific epithet is taken from the Latin "villosus" equals hairy, regarding the layer of short hairs on the body.

\section{Piesocorynus parvocorpus sp. nov. Figure 13}

\section{zoobank.org/3E38EFFE-6D85-4CB0-8FBF-E763D5815DAF}

Holotype. Probably female. Deposited in the PACO (accession \# C-105).

Description. Length body, $2.5 \mathrm{~mm}$; length rostrum, $1.0 \mathrm{~mm}$. Body brown with covering of dense, pale, appressed setae. Rostrum short, equal in length and width, 0.6 times as long as pronotum, flattened, without dorsal median carina, punctate; antennal scrobes foveiform, lateral; forehead wide, flattened, punctate; eyes coarsely faceted, fewer than 26 rows of ommatidia perpendicular to long axis, not emarginate, large, weakly convex, rounded; vertex weakly convex, densely punctate; temples short; antennae inserted in first third of rostrum, elongate, not reaching humeri; funicle with second to eighth antennomeres elongate-conical; club not compact, quite wide. Pronotum bell- shaped; 1.0 times longer than wide at apex, 0.8 times longer than wide in middle and at base, with quite long lateral carinae; disk weakly flattened, densely punctate, transverse dorsal pronotal carina antebasal; distance between transverse carina and base of pronotum 0.13 times as long as pronotum; scutellum trapezoidal. Elytra weakly flattened, 1.3 times longer than wide at base and in middle, 1.4 times longer than wide at apical fourth, 2.0 times as long as pronotum; greatest width at humeri and behind middle; elytron without tubercle; humeri convex; striae regular and thin; strial punctures small, rounded and dense; elytral intervals flattened, wide, 8.0-10.0 times as wide as points in striae, weakly punctate; apices of elytra not rounded; pygidium not concealed. Thorax punctate; precoxal portion of prosternum elongate, 1.3 times as long as length of procoxal cavity; postcoxal portion short; procoxal cavities narrowly separated; mesocoxal cavities widely separated, metanepisternum narrow. Abdomen convex; second ventrite 0.8 times as long as length of first ventrite; third ventrite 1.1 times as long as length of second ventrite; fourth ventrite 1.2 times as long as length of third ventrite; fifth ventrite 1.1 times as long as length of fourth ventrite. Legs long; proand mesocoxae round; metacoxae transverse; femora clavate, without teeth; trochanters obconical; mesofemora 2.6 times longer than wide in middle; metafemora 3.3 times longer than wide in middle; tibiae almost straight; metatibiae 8.8 times longer than wide in middle; tarsi long; first to third tarsomeres conical; second tarsomere embracing third tarsomere laterally; fifth elongate; tarsomeres with pulvilli on underside; tarsal claws free, large, diverging, with basal teeth.

Type locality. Amber mine in Chiapas Highlands of the Simojovel area in Chiapas, Mexico.

Etymology. The specific epithet is from the Latin "parvus" equals small, and the Latin "corpus" equals body, in reference to the small size of the fossil.

\section{Genus PIEZOBARRA Jordan, 1906 \\ Piezobarra brevisensoriata sp. nov. Figure 14}

zoobank.org/DAF892AA-5B3A-44DA-8A5F-BD30DF8396EC Holotype. Deposited in the PACO (accession \# C91).

Description. Length body, $4.4 \mathrm{~mm}$; length rostrum, $1.3 \mathrm{~mm}$. Body black with covering of dark, appressed setae; pronotum and elytra without spots of setae. Rostrum wide, short, 0.4 times as long as pronotum, flattened, without dorsal median carina; antennal scrobes foveiform, lateral; fore- 

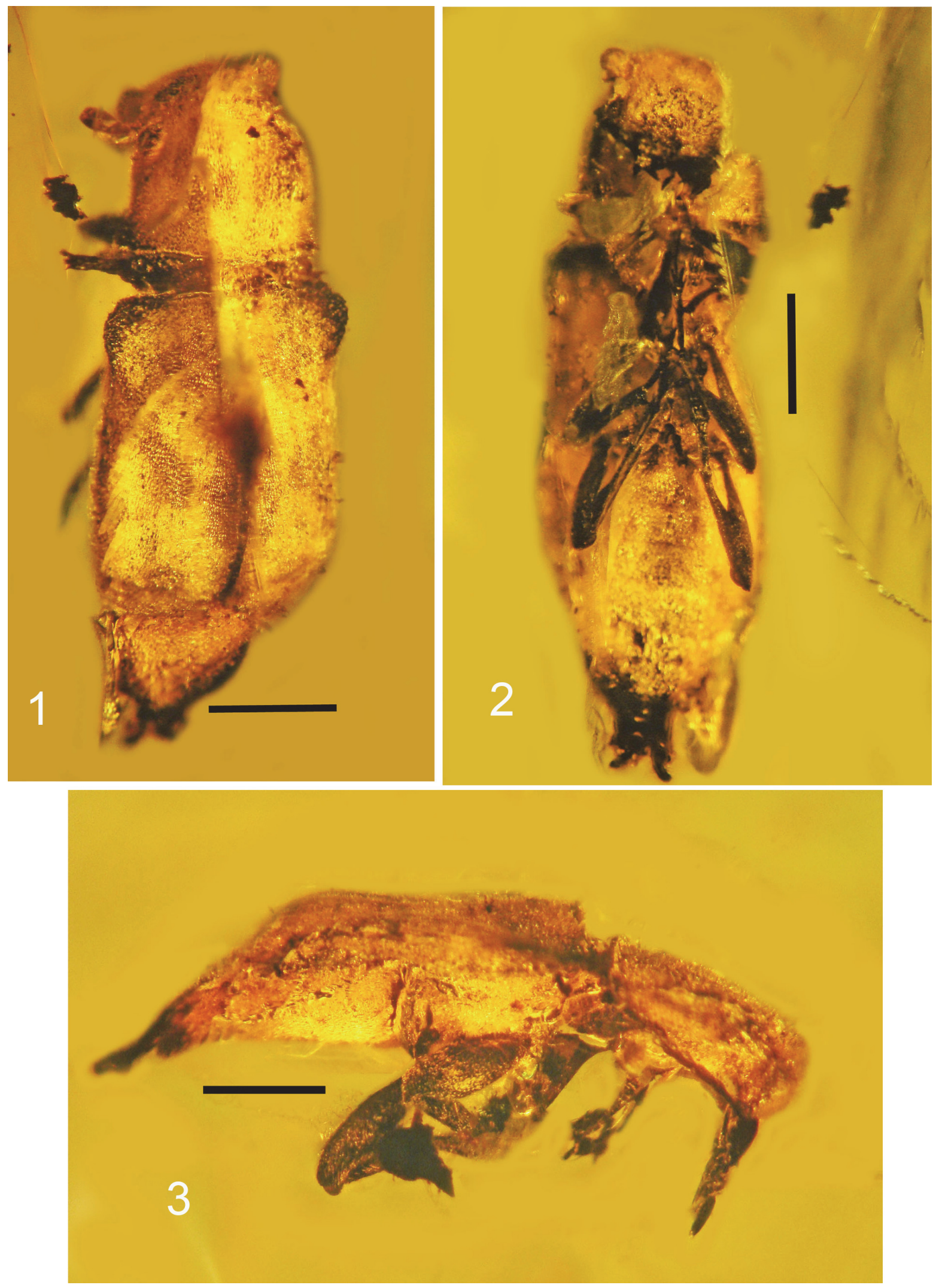

FIGURE 13. Holotype of Piesocorynus parvocorpus sp. nov. PACO no. C-105 in Mexican amber. 1, dorsal view, scale bar equals $0.5 \mathrm{~mm} ; 2$, ventral view, scale bar equals $0.4 \mathrm{~mm}$; and $\mathbf{3}$, lateral view, scale bar equals $0.4 \mathrm{~mm}$. 

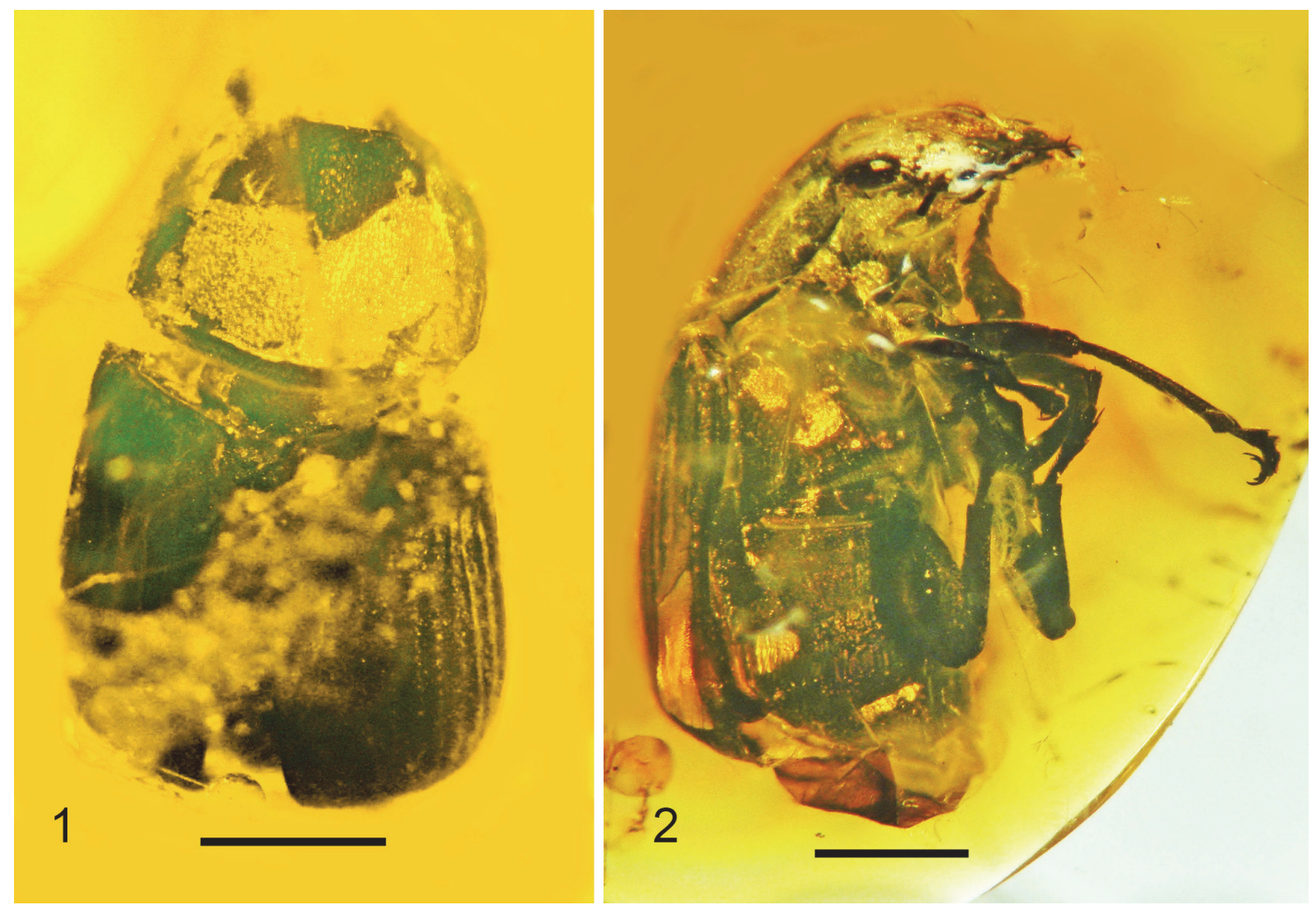

FIGURE 14. Holotype of Piezobarra brevisensoriata sp. nov. PACO no. C-91 in Dominican amber. 1, dorsal view, scale bar equals $1.2 \mathrm{~mm}$; and 2, lateral view, scale bar equals $1.0 \mathrm{~mm}$.

head wide, flat, densely punctate; eyes coarsely faceted, fewer than 26 rows of ommatidia perpendicular to long axis, not emarginate, large, convex, oval, 1.5 times longer than wide; vertex weakly convex, densely punctate; temples short; antennae inserted in first third of rostrum, quite short, reaching humeri; funicle with second to eighth antennomeres conical; seventh antennomere 2.0 times longer than wide; eighth antennomere 0.9 times longer than wide, 1.2 times as long as and 2.7 times as wide as seventh antennomere; club not compact, broad; first antennomere of club 0.5 times longer than wide, 1.1 times as long as and 1.9 times as wide as eighth antennomere; second antennomere of club 0.6 times longer than wide, subequal in length and 0.8 times as narrow as first antennomere of club; third antennomere of club 0.9 times longer than wide, subequal in length and 0.7 times as narrow as second antennomere of club. Pronotum wide-bell-shaped; 1.4 times longer than wide at apex, 0.9 times longer than wide in middle and 0.8 times longer than wide at base, with long lateral carinae; disk weakly flattened, densely punctate, transverse dorsal pronotal carina almost basal; scutellum trapezoidal. Elytra weakly convex, 1.0 times longer than wide at base, 0.8 times longer than wide in middle, 1.2 times longer than wide at apical fourth, 1.4 times as long as pronotum; greatest width behind middle; elytron without tubercle; humeri weakly convex; striae regular and thin; strial punctures rounded and dense; elytral intervals weakly convex, quite wide, 1.7-2.4 times as wide as points in striae; apices of elytra not rounded; pygidium not concealed. Thorax punctate; precoxal portion of prosternum elongate, equal in length to length of procoxal cavity; postcoxal portion short; procoxal cavities narrowly separated; mesocoxal cavities widely separated, metanepisternum broad, 2.8 times longer than wide in middle. Abdomen convex; first ventrite 1.2 times as long as length of metacoxal cavity; second ventrite 0.9 times as long as length of first ventrite; third ventrite equal in length to length of second ventrite; fourth ventrite 1.2 times as long as length of third ventrite; fifth ventrite 1.1 times as long as length of fourth ventrite. Legs long; proand mesocoxae round; metacoxae transverse; femora clavate, without teeth; trochanters obconi- 
cal; metafemora 2.4 times longer than wide in middle; tibiae almost straight; protibiae 7.9 times longer than wide in middle; metatibiae 6.3 times longer than wide in middle; tarsi long; first to third tarsomeres conical; second tarsomere embracing third tarsomere laterally; fifth elongate; tarsomeres with pulvilli on underside; tarsal claws free, large, diverging, with basal teeth; protarsi: first tarsomere 2.1 times longer than wide at base; second tarsomere 1.3 longer than wide at base, equal in length and 1.7 times as wide as first tarsomere; third tarsomere equal in length and width, 0.4 times as long as and 0.6 times as wide as second tarsomere; fifth tarsomere 3.3 times longer than wide at base, 0.9 times as long as and 0.3 times as wide as second tarsomere; metatarsi: first tarsomere 3.1 times longer than wide at base; second tarsomere 1.3 longer than wide at base, 0.7 times as long as and 1.7 times as wide as first tarsomere; third tarsomere equal in length and width, 0.5 times as long as and 0.6 times as wide as second tarsomere; fifth tarsomere 5.0 times longer than wide at base, 1.0 times as long as and 0.3 times as wide as second tarsomere.

Type locality. Amber mine in the Cordillera Septentrional of the northern portion of the Dominican Republic.

Etymology. The specific epithet is taken from the Latin "brevis" equals short, and the Latin "sentio" equals feel, in reference to the short antennae.

Comparison. This new species differs from $P$. sparsilis Jordan, 1906 from Central America by the larger and broader body size, longer lateral pronotal carina, shorter antennae, and pronotum and elytra lacking clusters of setae.

Remarks. This new species belongs to the genus Piezobarra Jordan, 1906 and is unique in having a basal transverse pronotal carina and very short antennae.

Subfamily CHORAGINAE Kirby, 1819

Tribe CHORAGINI Kirby, 1819

Genus CHORAGUS Kirby, 1819

Choragus exsertus sp. nov.

Figure 15

zoobank.org/C86DE9A8-770F-4918-954C-39EF8AC81A6F

Holotype. Deposited in the PACO (accession \# C90).

Paratypes. Deposited in the PACO (accession \# C-87 and C-98) and ISEA DA 2013/1.

Description. Length body, $1.8-2.0 \mathrm{~mm}$; length rostrum, $0.3-0.4 \mathrm{~mm}$. Body black with covering of dark, dense, appressed setae. Rostrum wide, 0.40.5 times as long as pronotum, flattened, without dorsal median carina; antennal scrobes foveiform, dorsal; forehead wide, flat, densely punctate; eyes elongate-oval, 0.9 times longer than wide, not emarginate, large, distinctly convex, upper ends closer than lower edges; vertex weakly convex, densely punctate; temples $0.4-1.2$ times as long as length of eye; antennae inserted dorsally at base of rostrum, elongate, reaching transversal prosternal carina; first antennomere (scape) 3.7 times longer than wide; funicle with second to eighth antennomeres elongate-conical; second antennomere 2.4-3.1 times longer than wide, equal in length and 1.5 times as wide as first antennomere; third antennomere 2.7 times longer than wide, 0.4 times as long as and 0.4 times as narrow as second antennomere; fourth antennomere 2.0 times longer than wide, 0.8 times as long as and 1.0 times as wide as third antennomere; fifth antennomere 1.7 times longer than wide, 0.8 times as long as and 1.0 times as narrow as fourth antennomere; sixth antennomere 1.7 times longer than wide, 1.0 times as long as and 1.0 times as narrow as fifth antennomere; seventh antennomere 3.0 times longer than wide, 1.4 times as long as and 1.0 times as wide as sixth antennomere; eighth antennomere 2.7 times longer than wide, 1.1 times as long as and 1.0 times as narrow as seventh antennomere; club not compact, wider than funicle, 0.3 times as long as funicle; first antennomere of club 2.0-2.4 times longer than wide, 1.5 times as long as and 2.0 times as wide as eighth antennomere; second antennomere of club 2.3-2.7 times longer than wide, 1.3 times as long as and 1.2 times as wide as first antennomere of club; third antennomere of club 3.0-3.3 times longer than wide, 0.4-1.1 times as long as and 1.0-1.1 times as wide as second antennomere of club. Pronotum wide-bell-shaped; 1.0-1.3 times longer than wide at apex, 0.6-0.9 times longer than wide in middle and 0.7-0.8 times longer than wide at base, with lateral carinae; disk weakly convex, densely punctate, transverse dorsal pronotal carina basal; scutellum wide-trapezoidal. Elytra convex, 0.9-1.0 times longer than wide at base, 0.9 times longer than wide in middle, $0.8-1.6$ times longer than wide at apical fourth, 1.4-1.5 times as long as pronotum; greatest width in middle; without clusters of setae; humeri weakly convex; striae regular and thin; strial punctures small, rounded, dense; elytral intervals flattened, quite narrow, 1.3-4.0 times as wide as striae, sparsely and gentle punctate; apices of elytra not rounded; pygidium not concealed. Thorax densely punctate; precoxal portion of prosternum long, 1.6 times as long as length of procoxal cavity, 4.0 times as long as postcoxal portion; post- 

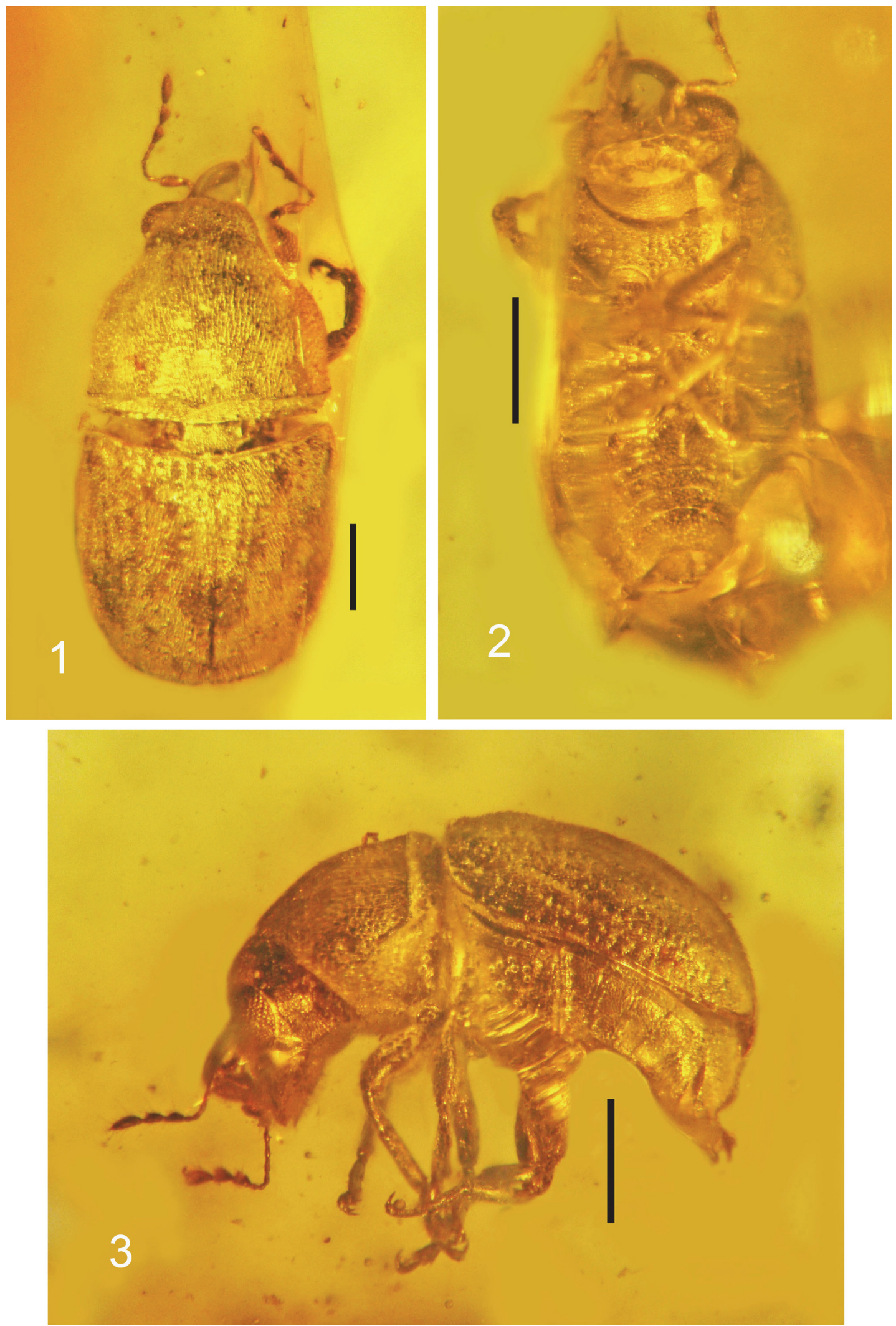

FIGURE 15. Holotype of Choragus exsertus sp. nov. PACO no. C-90 in Dominican amber. 1, dorsal view, scale bar equals $0.3 \mathrm{~mm}$; 2 , ventral view, scale bar equals $0.4 \mathrm{~mm}$; and 3 , lateral view, scale bar equals $0.4 \mathrm{~mm}$. 
coxal portion short, 0.4 times as long as length of procoxal cavity; procoxal cavities narrowly separated; mesocoxal cavities widely separated, metanepisternum narrow, 5.0-6.4 times longer than wide in middle. Abdomen convex; first ventrite $0.7-1.1$ times as long as length of metacoxal cavities; second ventrite $0.8-1.1$ times as long as length of first ventrite; third ventrite $0.7-1.0$ times as long as length of second ventrite; fourth ventrite 1.0 times as long as length of third ventrite; fifth ventrite 1.3-1.9 times as long as length of fourth ventrite. Legs long; pro- and mesocoxae round; metacoxae transverse, almost reaching elytral margin; femora clavate, without teeth; trochanters obconical; profemora 2.9-3.3 times longer than wide; mesofemora 4.3 times longer than wide; metafemora 2.7-3.3 times longer than wide; tibiae almost straight; protibiae 6.0-7.4 times longer than wide in middle; mesotibiae 4.9 times longer than wide in middle; metatibiae 5.3-6.0 times longer than wide in middle; tarsi long; first to third tarsomeres conical; second tarsomere embracing third tarsomere laterally; fifth elongate; tarsomeres with pulvilli on underside; tarsal claws free, large, diverging, with basal teeth; protarsi: first tarsomere 1.4-1.7 times longer than wide at base; second tarsomere 0.9-1.1 times longer than wide, 0.6-0.9 times as long as and 1.2 times as wide as first tarsomere; third tarsomere subequal in length and width, 0.5 times as long as and 0.4 times as wide as second tarsomere; fifth tarsomere 2.4-3.5 times longer than wide at base, $0.9-1.0$ times as long as and $0.5-0.8$ times as wide as second tarsomere; metatarsi: first tarsomere 2.8 times longer than wide at base; second tarsomere 1.6 times longer than wide, $0.5-0.7$ times as long as and 1.3 times as wide as first tarsomere; third tarsomere equal in length and width, 0.4 times as long as and 0.6 times as wide as second tarsomere; fifth tarsomere 4.0 times longer than wide at base, 1.0 times as long as and 0.4 times as wide as second tarsomere.

Type locality. Amber mine in the Cordillera Septentrional of the northern portion of the Dominican Republic.

Etymology. The specific epithet is taken from the Latin "exsertus" equals protruding, in reference to the protruding eyes.

Comparison. This species is similar to Ch. major Valentine, 1999 from the USA but differs by the smaller body size, broader body, and flattened elytral intervals.

Remarks. The new species is assigned to the tribe Araecerini based on the basal transverse pronotal carina, elongate-oval eyes with the upper edges closer than lower edges, and the elongate-transverse metacoxae that almost reach the elytral margin. Placement in the genus Choragus is based on the antennae with 11 antennomeres and the antennal club being wider than the funicle.

Tribe VALENFRIESIINI Alonso-Zarazaga and Lyal, 1999

Genus NEOXENUS Valentine, 1999 Neoxenus globosus sp. nov.

Figure 16

zoobank.org/CD8E9E39-6FD2-4259-B69D-159F2BE516F3

Holotype. Deposited in the PACO (accession \# C93).

Description. Length body, $2.9 \mathrm{~mm}$; length rostrum, $0.5 \mathrm{~mm}$. Body black with covering of dark dense, decumbent setae. Rostrum wide, 0.6 times longer than wide in middle, 0.4 times as long as pronotum, weakly convex, without dorsal median carina; antennal scrobes foveiform, dorsal; forehead wide, convex, densely punctate; eyes rounded, not emarginate, large, weakly convex, equal in length and width, upper edges not closer than lower edges; vertex weakly convex, densely punctate; temples short, 0.2 times as long as length of eye; antennae inserted dorsally at base of rostrum, elongate, almost reaching base of pronotum; first antennomere (scape) 2.8 times longer than wide; funicle with second to eighth antennomeres elongate-conical; second antennomere 2.0 times longer than wide, 0.7 times as long as and subequal in length to first antennomere; third to fifth antennomeres subequal in width; third antennomere 4.0 times longer than wide, 0.8 times as long as second antennomere; fourth antennomere 2.7 times longer than wide, 0.7 times as long as third antennomere; fifth antennomere 3.3 times longer than wide, 1.3 times as long as wide as fourth antennomere; club not compact, 0.7 times as long as funicle; first antennomere of club 2.0 times longer than wide; second antennomere of club 1.3 times longer than wide, 1.5 times as long as and equal to first antennomere of club; third antennomere of club 2.0 times longer than wide, subequal in length and 0.7 times as narrow as second antennomere of club. Pronotum bell-shaped; 1.3 times longer than wide at apex, 0.9 times longer than wide in middle and at base, without lateral carinae; disk weakly convex, densely punctate, transverse dorsal pronotal carina antebasal; distance between transverse carina and base of pronotum 0.17 times as long as pronotum; scutellum wide-trapezoidal. Elytra convex, 2.0 times longer than wide at base, 1.6 times longer than wide in middle, 2.2 times longer than 

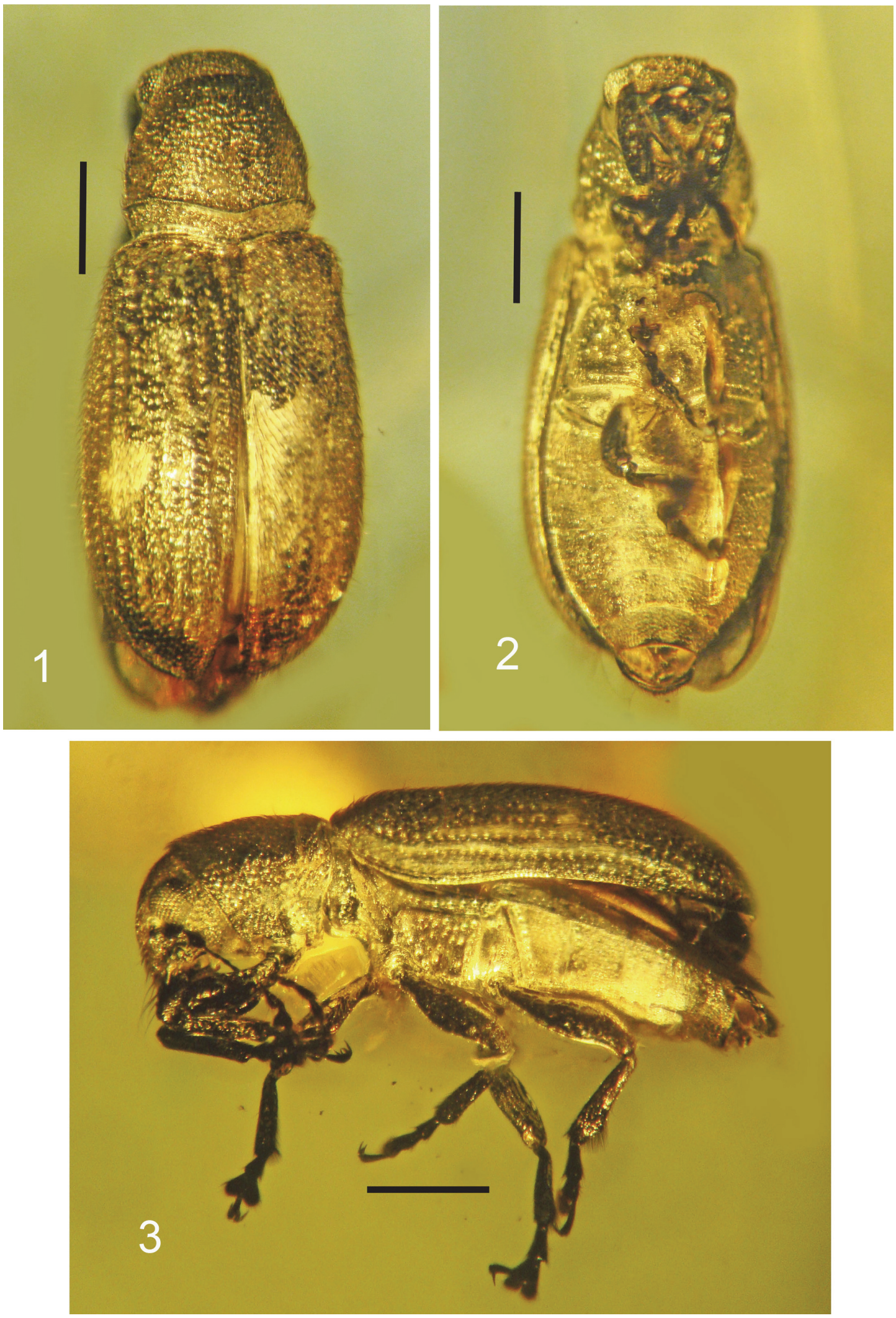

FIGURE 16. Holotype of Neoxenus globosus sp. nov. PACO no. C-93 in Dominican amber. 1, dorsal view, scale bar equals $0.4 \mathrm{~mm}$; 2, ventral view, scale bar equals $0.4 \mathrm{~mm}$; and 3, lateral view, scale bar equals $0.4 \mathrm{~mm}$. 
wide at apical fourth, 2.7 times as long as pronotum; greatest width behind middle; without spots of setae; humeri weakly flattened; striae regular and thin; strial punctures small, rounded, dense; elytral intervals weakly convex, wide, 2.5-3.0 times as wide as striae, sparsely and weakly punctate; apices of elytra not rounded; pygidium not concealed. Thorax punctate; prosternum coarsely punctate; precoxal portion of prosternum 0.5 times as long as procoxal cavities, 0.8 times as long as postcoxal portion; postcoxal portion 0.7 times as long as procoxal cavities; procoxal cavities narrowly separated; mesocoxal cavities widely separated, metanepisternum narrow, 6.4 times longer than wide in middle. Abdomen convex; first ventrite 1.3 times as long as length of metacoxal cavity; second ventrite equal in length to length of first ventrite; third ventrite 0.8 times as long as length of second ventrite; fourth ventrite 0.9 times as long as length of third ventrite; fifth ventrite 0.9 times as long as length of fourth ventrite. Legs long; proand mesocoxae round; metacoxae transverse, almost reaching elytral margin; femora clavate, without teeth; trochanters obconical; profemora 3.1 times longer than wide; mesofemora 3.5 times longer than wide; metafemora 3.6 times longer than wide; tibiae almost straight, flattened; protibiae 5.0 times longer than wide in middle; mesotibiae 4.0 times longer than wide in middle; metatibiae 3.9 times longer than wide in middle; tarsi long; first to third tarsomeres conical; second tarsomere embracing third tarsomere laterally; fifth elongate; tarsomeres with pulvilli on underside; tarsal claws free, large, diverging, with basal teeth; protarsi: first tarsomere 1.5 times longer than wide at base; second tarsomere 0.8 longer than wide at base, equal in length and 2.0 times as wide as first tarsomere; third tarsomere 0.8 times longer than wide, 0.4 times as long as and 0.4 times as wide as second tarsomere; fifth tarsomere 2.7 times longer than wide at base, 0.9 times as long as and 0.3 times as wide as second tarsomere; metatarsi: first tarsomere 2.2 times longer than wide at base; second tarsomere 1.1 longer than wide at base, 0.9 times as long as and 1.8 times as wide as first tarsomere; third tarsomere 0.8 times longer than wide, 0.3 times as long as and 0.5 times as wide as second tarsomere.

Type locality. Amber mine in the Cordillera Septentrional of the northern portion of the Dominican Republic.

Etymology. The specific epithet is taken from the Latin "globosus" equals round, in reference to the round eyes.
Comparison. The new species is close to $N$. versicolor Valentine, 1999 from southern North America and Central America but differs by the narrower body, black antennae and legs and elytra without setal spots.

Remarks. This and the following two species belong to the tribe Valenfriesiini because of the following features: antebasal transverse pronotal carina, rounded eyes, with upper edges not closer than lower edges, and elongate-transverse metacoxae, almost reaching the elytral margin. The absent lateral pronotal carina is a character of the genus Neoxenus.

\section{Genus CYPTOXENUS Valentine, 1982 \\ Cyptoxenus buchelus sp. nov.}

Figure 17

\section{zoobank.org/D7A43ECF-A285-401D-AFED-310457821DFF}

Holotype. Female; deposited in the PACO (accession \# C-88).

Description. Length body, $2.5 \mathrm{~mm}$; length rostrum, $0.3 \mathrm{~mm}$. Body black with covering of dark dense, decumbent setae. Rostrum wide, 0.3 times as long as pronotum, weakly convex, without dorsal median carina; antennal scrobes foveiform, dorsal; forehead wide, weakly convex, densely punctate; eyes rounded, not emarginate, large, distinctly convex, 0.9 times longer than wide, upper edges not closer than lower edges; vertex weakly convex, densely punctate; temples short; antennae inserted dorsally at base of rostrum, elongate, almost reaching base of pronotum; first antennomere (scape) 6.0 times longer than wide; funicle with second to eighth antennomeres elongate-conical; second antennomere 5.7 times longer than wide, 1.1 times as long as and 1.2 times as wide as first antennomere; third to sixth antennomeres subequal; third antennomere 5.8 times longer than wide, 0.4 times as long as and 0.4 times as narrow as second antennomere; seventh antennomere 2.5 times longer than wide, 0.7 times as long as and 1.7 times as wide as sixth antennomere; eighth antennomere 2.0 times longer than wide, 0.8 times as long as and subequal in width to seventh antennomere; club not compact, quite narrow, 0.6 times as long as funicle; first antennomere of club 2.3 times longer than wide, 1.8 times as long as and 1.5 times as wide as eighth antennomere; second antennomere of club 3.7 times longer than wide, 1.6 times as long as and subequal in width to first antennomere of club; third antennomere of club 4.3 times longer than wide, 1.4 times as long as and 1.2 times as narrow as second antennomere of club. Pronotum bell-shaped; 2.2 times longer than wide at apex, 1.0 times longer than wide in middle 

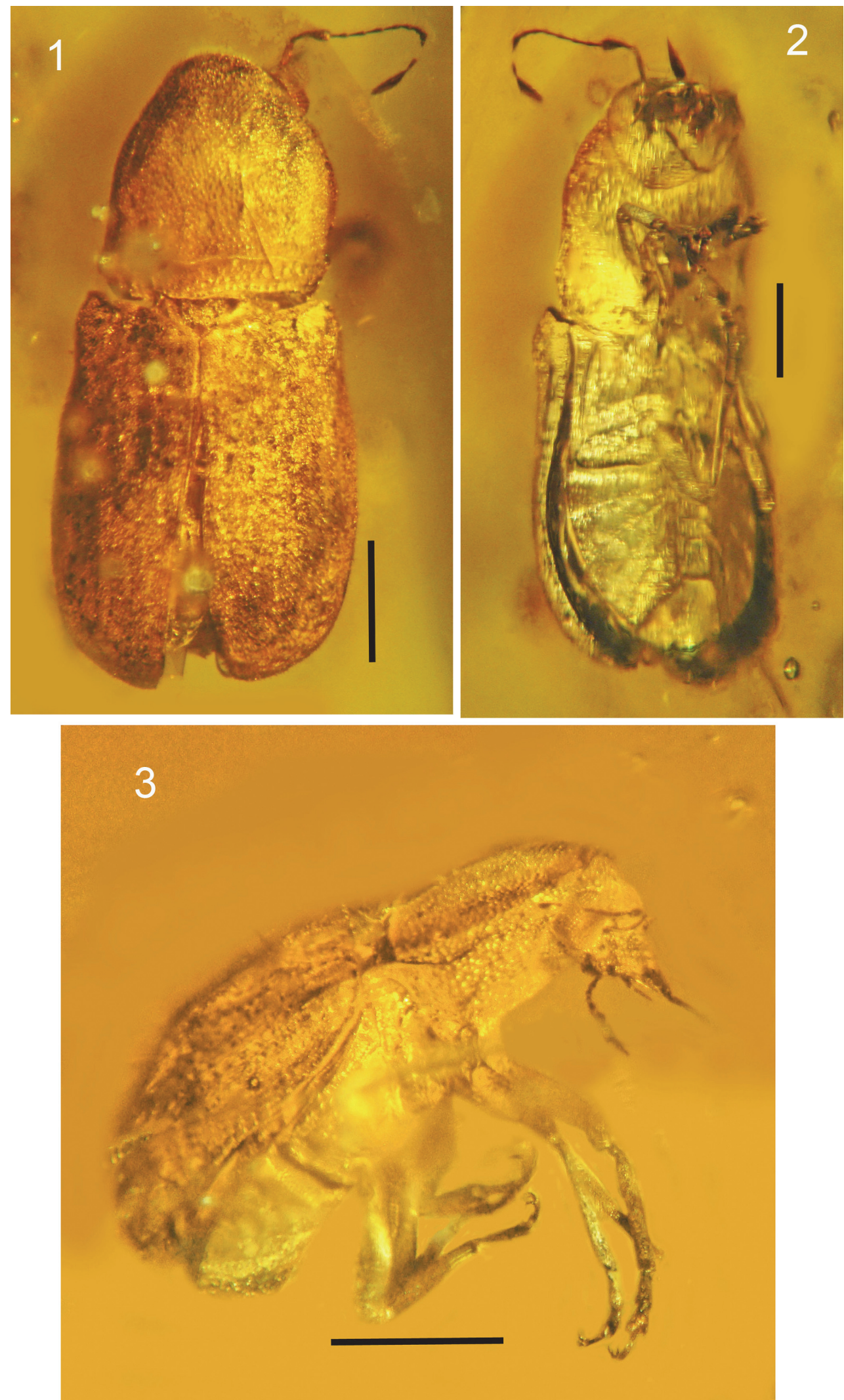

FIGURE 17. Holotype of Cyptoxenus buchelus sp. nov. PACO no. C-88 in Dominican amber. 1, dorsal view, scale bar equals $0.5 \mathrm{~mm}$; 2 , ventral view, scale bar equals $0.4 \mathrm{~mm}$; and 3 , lateral view, scale bar equals $0.7 \mathrm{~mm}$. 
and 1.2 times longer than wide at base, with lateral carinae; disk weakly flattened, densely punctate, transverse dorsal pronotal carina antebasal; distance between transverse carina and base of pronotum 0.16 times as long as pronotum; scutellum wide-trapezoidal. Elytra convex, 1.5 times longer than wide at base, 1.2 times longer than wide in middle, 1.8 times longer than wide at apical fourth, 1.5 times as long as pronotum; greatest width behind middle; without spots of setae; humeri weakly convex; striae regular and thin; strial punctures small, rounded, dense; elytral intervals weakly convex, quite wide, $2.0-2.8$ times as wide as striae, sparsely and weakly punctate; apices of elytra not rounded; pygidium not concealed. Thorax densely punctate; prosternum coarsely punctate; precoxal portion of prosternum 1.4 times as long as procoxal cavities, 4.0 times as long as postcoxal portion; postcoxal portion 0.4 times as long as procoxal cavities; procoxal cavities narrowly separated; mesocoxal cavities widely separated, metanepisternum narrow, 6.2 times longer than wide in middle. Abdomen convex; first ventrite 0.9 times as long as length of metacoxal cavity; second ventrite 1.1 times as long as length of first ventrite; third ventrite equal in length to length of second ventrite; fourth ventrite 0.7 times as long as length of third ventrite; fifth ventrite 1.3 times as long as length of fourth ventrite. Legs long; proand mesocoxae round; metacoxae transverse, almost reaching elytral margin; femora clavate, without teeth; trochanters obconical; profemora 3.2 times longer than wide; mesofemora 2.9 times longer than wide; metafemora 4.1 times longer than wide; tibiae almost straight; protibiae 9.7 times longer than wide in middle; metatibiae 7.0 times longer than wide in middle; tarsi long; first to third tarsomeres conical; second tarsomere embracing third tarsomere laterally; fifth elongate; tarsomeres with pulvilli on underside; tarsal claws free, large, diverging, with basal teeth; protarsi: first tarsomere 2.3 times longer than wide at base; second tarsomere equal in length and width, 0.7 times as long as and 1.7 times as wide as first tarsomere; third tarsomere subequal in length and width, 0.6 times as long as and 0.7 times as wide as second tarsomere; fifth tarsomere 5.0 times longer than wide at base, 2.0 times as long as and 0.4 times as wide as second tarsomere; metatarsi: second tarsomere 0.6 times as long as first tarsomere; third tarsomere 0.6 times as long as second tarsomere; fifth tarsomere 2.7 times as long as second tarsomere.
Type locality. Amber mine in the Cordillera Septentrional of the northern portion of the Dominican Republic.

Etymology. The specific epithet is taken from the Latin "bu" equals large (as a prefix) and the Latin "chela" equals claw, in reference to the large claws.

Comparison. The new species differs from C. sigillatus Valentine, 1982 from Jamaica by the elongate body, narrower antennal club and absence of setal spots on the first and second antennomeres and elytra.

Remarks. Both new species are placed in the genus Cyptoxenus because of the lateral pronotal carina, weakly convex elytral humeri and pubescent body.

\section{Cyptoxenus ovatus sp. nov.}

Figure 18

\section{zoobank.org/F5E5048E-EA90-409D-9165-4B767CBA1B33}

Holotype. Female; deposited in the PACO (accession \# C-96).

Description. Length body, $2.5 \mathrm{~mm}$; length rostrum, $0.3 \mathrm{~mm}$. Body black with covering of dark dense decumbent setae. Rostrum wide, 0.4 times as long as pronotum, flattened, without dorsal median carina; antennal scrobes foveiform, dorsal; forehead wide, flat, densely punctate; eyes almost rounded, not emarginate, large, distinctly convex, upper edges not closer than lower edges; vertex weakly convex, densely punctate; temples short; antennae inserted dorsally at base of rostrum, elongate, reaching transversal prosternal carina; first antennomere (scape) 2.7 times longer than wide; funicle with second to eighth antennomeres elongate-conical; second antennomere 2.3 times longer than wide, equal in length and 1.2 times as wide as first antennomere; third to sixth antennomeres subequal in width; third antennomere 2.7 times longer than wide, 0.5 times as long as and 0.4 times as narrow as second antennomere; fourth antennomere 3.0 times longer than wide, 0.9 times as long as and equal in length to third antennomere; fifth antennomere subequal to fourth antennomere; sixth antennomere 2.0 times longer than wide, 0.9 times as long as fifth antennomere; seventh antennomere 1.9 times longer than wide, 1.2 times as long as and 1.2 times as wide as sixth antennomere; eighth antennomere 1.7 times longer than wide, 0.9 times as long as and subequal in width to seventh antennomere; club not compact, quite narrow, 0.8 times as long as funicle; first antennomere of club 3.0 times longer than wide, 3.0 times as long as and 1.7 times as wide as eighth antennomere. Pronotum bell-shaped; 1.4 times longer than wide at apex, 0.8 times longer 

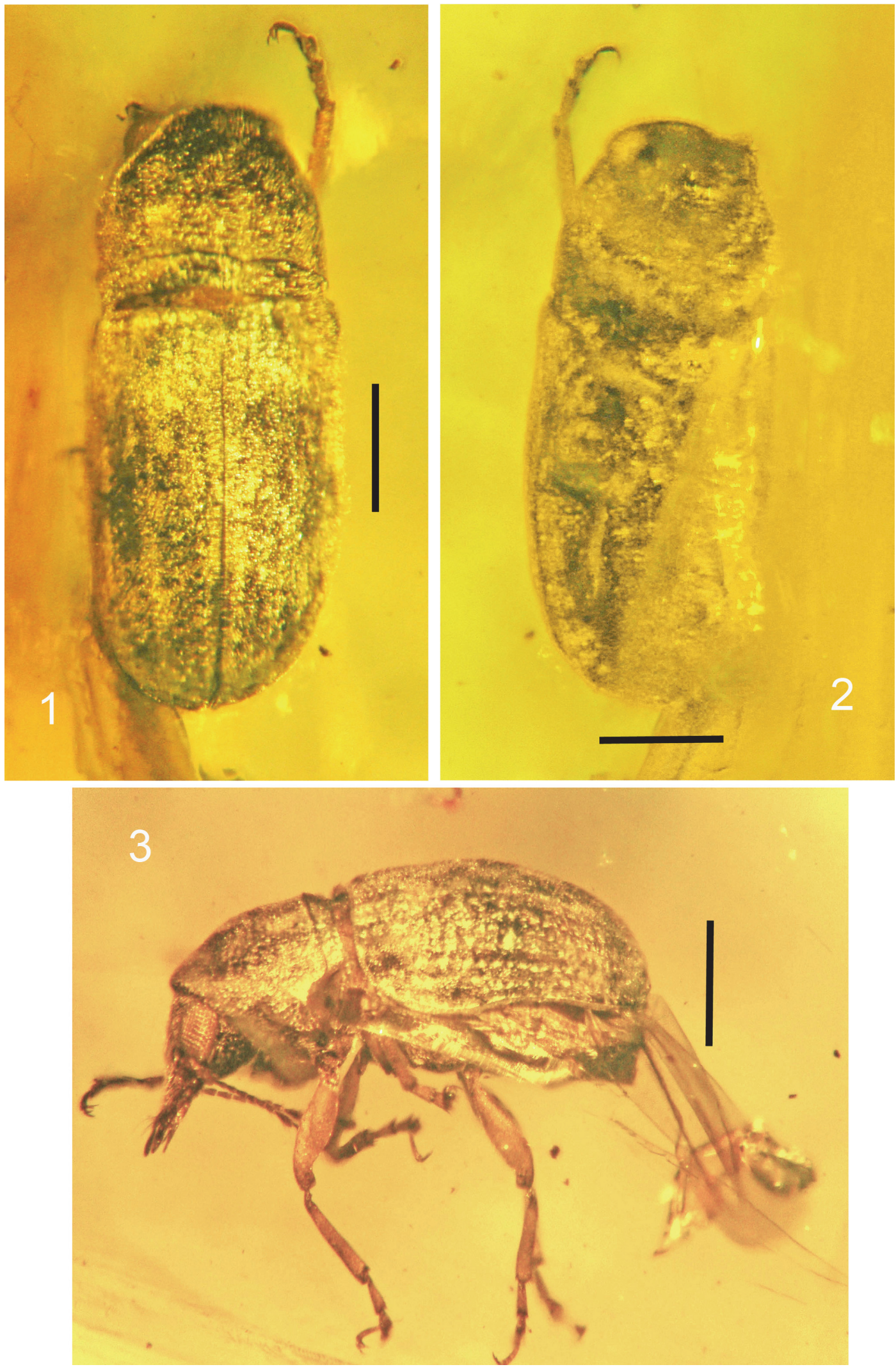

FIGURE 18. Holotype of Cyptoxenus ovatus sp. nov. PACO no. C-96 in Dominican amber. 1, dorsal view, scale bar equals $0.5 \mathrm{~mm} ; 2$, ventral view, scale bar equals $0.5 \mathrm{~mm}$; and $\mathbf{3}$, lateral view, scale bar equals $0.6 \mathrm{~mm}$. 
than wide in middle and at base, with lateral carinae; disk weakly convex, densely punctate, transverse dorsal pronotal carina antebasal; distance between transverse carina and base of pronotum 0.11 times as long as pronotum; scutellum widetrapezoidal. Elytra convex, 1.7 times longer than wide at base, 1.5 times longer than wide in middle, 2.9 times longer than wide at apical fourth, 2.4 times as long as pronotum; greatest width behind middle; without spots of setae; humeri weakly convex; striae regular and thin; strial punctures small, rounded, dense; elytral intervals flattened, quite narrow, 1.3-2.0 times as wide as striae, sparsely and weakly punctate; apices of elytra not rounded; pygidium not concealed. Thorax densely punctate; precoxal portion of prosternum long; postcoxal portion short; procoxal cavities narrowly separated; mesocoxal cavities widely separated, metanepisternum narrow. Abdomen convex; first ventrite 1.2 times as long as length of metacoxal cavities; second ventrite equal in length to length of first ventrite; third ventrite 0.9 times as long as length of second ventrite; fourth ventrite 0.9 times as long as length of third ventrite; fifth ventrite 1.1 times as long as length of fourth ventrite. Legs long; proand mesocoxae round; metacoxae transverse, almost reaching elytral margin; femora clavate, without teeth; trochanters obconical; profemora 3.8 times longer than wide; metafemora 4.3 times longer than wide; tibiae almost straight; protibiae 6.7 times longer than wide in middle; metatibiae 5.8 times longer than wide in middle; tarsi long; first to third tarsomeres conical; second tarsomere embracing third tarsomere laterally; fifth tarsomere elongate; tarsomeres with pulvilli on underside; tarsal claws free, large, diverging, with basal teeth; protarsi: first tarsomere 3.3 times longer than wide at base; second tarsomere 1.6 times longer than wide, 0.6 times as long as and 1.3 times as wide as first tarsomere; third tarsomere subequal in length and width, 0.5 times as long as and 0.8 times as wide as second tarsomere; fifth tarsomere 4.0 times longer than wide at base, 1.3 times as long as and 0.5 times as wide as second tarsomere; mesotarsi: first tarsomere 2.3 times longer than wide at base; second tarsomere equal in length and width, 0.7 times as long as and 1.5 times as wide as first tarsomere; metatarsi: first tarsomere 3.3 times longer than wide at base; second tarsomere 1.4 times longer than wide, 0.5 times as long as and 1.3 times as wide as first tarsomere; third tarsomere equal in length and width, 0.4 times as long as and 0.6 times as wide as second tarsomere; fifth tarsomere 4.4 times longer than wide at base, 3.7 times as long as and 0.8 times as wide as second tarsomere.

Type locality. Amber mine in the Cordillera Septentrional of the northern portion of the Dominican Republic.

Etymology. The specific epithet is taken from the Latin" ovatus" equals oval, in reference to the oval shape of the eyes of the fossil.

Comparison. The new species is similar to $C$. buchelus sp. nov. but differs by the narrower body, shorter lateral pronotal carina and smaller body size.

\section{DISCUSSION}

The oldest and most primitive Anthribidae, in the subfamily Juranthribinae, date from the Middle-Upper Jurassic (Legalov, 2011). The other Jurassic subfamily, the Protoscelinae, was described in the family Chrysomelidae (Medvedev, 1968) and transferred to the family Anthribidae (Legalov, 2012b, 2013b, 2015). The first representatives of the subfamily Anthribinae are known from the Albian of Russia (Zherikhin, 1993; Gratshev and Legalov, 2014; Legalov, 2015) and the subfamily Choraginae from the Berriasian-Barremian of Spain (Soriano et al., 2006; Legalov, 2015). Anthribidae are not yet known from Cretaceous Burmese amber (Legalov and Poinar, 2015) and other Cretaceous deposits (Davis at al., 2013; Legalov, 2014a, 2014b, 2015; Peris et al., 2014). A rich anthribid fauna was described from Upper Eocene Baltic and Rovno ambers (Gratshev and Perkovsky, 2008; Legalov, 2012a, 2013a, 2015). Impressions of Anthribidae are known from the Eocene, Oligocene and Miocene (Legalov, 2015). Up until the present, no Anthribidae have been described from Dominican or Mexican amber.

The anthribid fauna of the New World is poorly understood (Jordan, 1904, 1906, 1937; Valentine, 2003) with only the North America fauna studied in detail (Valentine, 1960, 1999). The majority of the West Indies species have not been described (Valentine, 2003). However, some comparisons of the present fossils with the modern fauna can be made. In Mexican amber are two genera; Piesocorynus with four species and Euparius with one species. While six Piesocorynus species are known today from Central America (Rheinheimer, 2004), only $P$. lateralis Jordan, 1906 have been recorded from Mexico (Valentine, 1999). The present study establishes 13 species in the genera Toxonotus, Eugonus, Piesocorynus (see Appendix), Piezobarra, Choragus, Neoxenus and Cyptoxenus from Dominican amber. These are the first records of 
the genera Eugonus, Piezobarra, Choragus, Neoxenus and Cyptoxenus in the fauna of Hispaniola. The most species-rich genera, Homocloeus Jordan, 1904 and Ormiscus Waterhouse, 1845 from Hispaniola (Perez-Gelabert, 2008) have not yet been found in amber.

Currently the Mexican amber weevil fauna is represented by three species of the families Rhynchitidae and Curculionidae (Zimmermann, 1971; Poinar and Brown, 2007), while Dominican amber contains some 90 species of the families Belidae, Rhynchitidae, Attelabidae, Brentidae and Curculionidae (Davis and Engel, 2006a, 2006b, 2006c, 2007, 2009; Poinar, 2009; Poinar and Brown, 2011; Poinar et al., 2013, 2016; Poinar and Legalov, 2014a, 2014b, 2014c, 2014d, 2015a, 2015b 2015c, 2015d, 2015e, 2015f). The above descriptions of Anthribidae add yet another family of curculionid beetles to the New World amber faunas.

\section{ACKNOWLEDGMENTS}

The authors are grateful to Alex E. Brown for supplying many of the specimens included in the present study. The study was partially supported by the Federal Fundamental Scientific Research Programme for 2013-2020, project no. VI.51.1.7 and the Russian Foundation for Basic Research, project no. 15-04-02971a.

\section{REFERENCES}

Alonso-Zarazaga, M.A. and Lyal, C.H.C. 1999. A World Catalogue of Families and Genera Curculionoidea (Insecta: Coleoptera) (Excepting Scolytidae and Platypodidae). Entomopraxis, Barcelona.

Alonso-Zarazaga, M.A. and Lyal, C.H.C. 2002. Addenda and corrigenda to 'A World Catalogue of Families and Genera of Curculionoidea (Insecta: Coleoptera)'. Zootaxa, 63:1-37.

Billberg, G.J. 1820. Enumeratio Insectorum in Musaeo Gust. Joh. Billberg. Typis Gadelianis, Stockholm. (In Latin)

Davis, S.R. and Engel, M.S. 2006a. A zygopine weevil in Early Miocene amber from the Dominican Republic (Coleoptera; Curculionidae). Caribbean Journal of Science, 42:255-257.

Davis, S.R. and Engel, M.S. 2006b. A weevil of the genus Caulophilus in Dominican amber (Coleoptera: Curculionidae). Polish Journal of Entomology, 75:101-104.

Davis, S.R. and Engel, M.S. 2006c. Dryophthorine weevils in Dominican amber (Coleoptera: Curculionidae). Transactions of the Kansas Academy of Science, 109:191-198.

Davis, S.R. and Engel, M.S. 2007. Cossonine weevils in Dominican amber (Coleoptera: Curculionidae). Linzer Biologische Beiträge, 39:803-820.
Davis, S.R. and Engel, M.S. 2009. An orthognathine weevil of the genus Mesocordylus in Dominican amber. Beiträge zur Entomologie, 59:233-238.

Davis, S.R., Engel, M.S., Legalov, A.A., and Ren, D. 2013. Weevils of the Yixian formation, China (Coleoptera: Curculionoidea): phylogenetic considerations and comparison with other Mesozoic faunas. Journal of Systematic Palaeontology, 11:399-429.

Dejean, P.F.M.A. 1834. Catalogue de la collection de Coléoptères de M. le Baron Dejean. 3. MéquignonMarvis, Paris. (in French)

Draper, G., Mann, P., and Lewis, J.F. 1994. Hispaniola, p. 129-150. In Donovan, S. and Jackson, T.A. (eds.), Caribbean Geology: An Introduction. The University of the West Indies Publishers' Association, Kingston, Jamaica.

Fahraeus, O.I. 1839. [Title and pages unknown] In: Schoenherr, C.J. (ed.), Genera et species curculionidum, cum synonymia hujus familiae. Species novae out hactenus minus cognitae, descriptionibus a Dom. Leonardo Gyllenhal, C. H. Boheman, et entomologis aliis illustratae, 5(1). Paris, Roret. (in Latin)

Gratshev, V.G. and Legalov, A.A. 2014. The Mesozoic stage of evolution of the family Nemonychidae (Coleoptera, Curculionoidea). Paleontological Journal, 48:851-944.

Gratshev, V.G. and Perkovsky, E.E. 2008. New species of the genus Glaesotropis (Insecta: Coleoptera: Anthribidae) from Rovno amber, Paleontological Journal, 42:60-63.

Iturralde-Vinent, M.A. and MacPhee, R.D.E. 1996. Age and paleogeographic origin of Dominican amber. Science, 273:1850-1852.

Jordan, K. 1904. American Anthribidae. Novitates Zoologicae, 11:242-309.

Jordan, K. 1906. Insecta. Coleoptera. Rhynchophora. Anthribidae. Biologia Centrali-Americana, 4(6):315246, 347-362.

Jordan, K. 1937. Anthribidae from South and Central America. Novitates Zoologicae, 40:208-261.

Kirby, W. 1819. A century of Insects, including several new genera described from his cabinet. Transactions of the Linnean Society of London, 12:375-453.

Kuschel, G. 1995. A phylogenetic classification of Curculionoidea to families and subfamilies. Memoirs of the Entomological Society of Washington, 14:5-33.

Labram, D. and Imhoff, L. 1838. Singulorum generum Curculionidum unam alteramve speciem additis iconibus. Die Gattungen der Russelkafer erlautert durch bildliche Darslellung einzelner Arten. Verlag der Schweighauser'schen Buchhandlung, Basel. (In Latin)

Lacordaire, T. 1866. Histoire Naturelle des Insectes. Genera des Coléoptères ou exposé méthodique et critique de tous les genres proposés jusqu'ici dans cet ordre d'insectes. Vol. 7. Roret, Paris. (In French)

LeConte, J.L. and Horn, G.H. 1876. The Rhynchophora of America north of Mexico. Proceedings of the American Philosophical Society, 15:1-455. 
Legalov, A.A. 2011. First record of Anthribid beetles from the Jurassic of Kazakhstan (Coleoptera: Anthribidae). Paleontological Journal, 45:629-633.

Legalov, A.A. 2012a. New Curculionoid beetles (Coleoptera: Curculionoidea) from the Baltic amber. Paleontological Journal, 46:262-272.

Legalov, A.A. 2012b. Fossil history of Mesozoic weevils (Coleoptera: Curculionoidea). Insect Science, 19:683-698.

Legalov, A.A. 2013a. New and little known weevils (Coleoptera: Curculionoidea) from the Paleogene and Neogene. Historical Biology, 25:59-80.

Legalov, A.A. 2013b. Review of the family Anthribidae (Coleoptera) from the Jurassic of Karatau: subfamily Protoscelinae. Genus Protoscelis Medvedev. Paleontological Journal, 47:292-302.

Legalov, A.A. 2014a. The oldest Brentidae and Curculionidae (Coleoptera: Curculionoidea) from the Aptian of Bon-Tsagaan. Historical Biology, 26:6-15.

Legalov, A.A. 2014b. New Nemonychidae, Brentidae and Curculionidae (Coleoptera: Curculionoidea) from the Turonian of Kzyl-Dzhar (Kazakhstan). Historical Biology, 26:675-689.

Legalov, A.A. 2015. Fossil Mesozoic and Cenozoic weevils (Coleoptera, Obrienioidea, Curculionoidea). Paleontological Journal, 49:1442-1513.

Legalov, A.A. and Poinar, G.O., Jr. 2015. New tribes of the superfamily Curculionoidea (Coleoptera) in Burmese amber. Historical Biology, 27:558-564.

Louw, S. 1993. Systematics of the Urodontidae (Coleoptera: Curculionoidea) of southern Africa. Entomology Memoir of Department of Agriculture, Republic of South Africa, 87:1-92.

Medvedev, L.N. 1968. Leaf-beetles from the Jurassic of the Karatau (Coleoptera, Chrysomelidae). p. 155165. In Rohdendorf, B.B. (ed.), Yurskie nasekomye Karatau (Jurassic Insects of the Karatau), Nauka, Moscow. (in Russian)

Morimoto, K. 1972. A key to the genera of Oriental Anthribidae (Coleoptera). Bulletin of the Government Forest Experiment Station, 246:35-54.

Perez-Gelabert, D.E. 2008. Arthropods of Hispaniola (Dominican Republic and Haiti): a checklist and bibliography. Zootaxa, 1831:1-530.

Peris, D., Davis, S.R., Engel, M.S., and Delclòs, X. 2014. An evolutionary history embedded in amber: reflection of the Mesozoic shift in weevil dominated (Coleoptera: Curculionoidea) faunas. Zoological Journal of the Linnean Society, 171:534-553.

Pierce, W.D. 1916. Studies on weevils (Rhynchophora) with descriptions of new genera and species. Proceedings of the United States National Museum, 51:461-473.

Poinar, G.O., Jr. 1991. Hymenaea protera sp.n. (Leguminosae: Caesalpinoideae) from Dominican amber has African affinities. Experientia, 47:1075-1082.

Poinar, G.O., Jr. 2009. Dominibrentus leptus, n. gen., n. sp. (Curculionoidea, Brentidae, Cyphagoginae,
Dominibrentini, n. tribe), a straight snouted weevil in Dominican amber. Historical Biology, 21:51-55.

Poinar, G.O., Jr. and Brown, A.E. 2002. Hymenaea mexicana sp. nov. (Leguminosae: Caesalpinioideae) from Mexican amber indicates Old World connections. Botanical Journal of the Linnean Society, 139:125132.

Poinar, G.O., Jr. and Brown, A.E. 2007. Eugnamptus proterus sp. n. (Coleoptera: Curculionoidea: Rhynchitidae), a tooth-nosed snout beetle in Mexican amber. Proceedings of the Entomological Society of Washington, 109:880-885.

Poinar, G.O., Jr. and Brown, A.E. 2011. Descriptions of a broad-nosed weevil (Eudiagogini: Curculionidae) and false ladybird beetle (Nilionini: Nilionidae) in Dominican amber. Historical Biology, 23:231-235.

Poinar, G.O., Jr., Brown, A.E., and Legalov, A.A. 2016. First record of the genus Pseudopilolabus Legalov, 2003 (Coleoptera: Attelabidae) in Dominican amber. Fossil Record, 19:11-16.

Poinar, G.O., Jr. and Legalov, A.A. 2014a. Bicalcasura maculata n. gen., n. sp. (Curculionoidea: Dryopthtoridae) with a list of weevils described from Dominican amber. Historical Biology, 26:449-453.

Poinar, G.O., Jr. and Legalov, A.A. 2014b. New Cryptorhynchinae (Coleoptera: Curculionidae) in Dominican amber. Historical Biology, 26:502-534.

Poinar, G.O., Jr. and Legalov, A.A. 2014c. New species of the subfamily Conoderinae (Coleoptera: Curculionidae) in Dominican amber. Historical Biology, 26:556-562.

Poinar, G.O., Jr. and Legalov, A.A. 2014d. Pleurambus strongylus n. gen., n. sp. (Coleoptera: Belidae) in Dominican amber. Historical Biology, 26:670-674.

Poinar, G.O., Jr. and Legalov, A.A. 2015a. First record of the genus Baris Germar, 1817 (Coleoptera: Curculionidae), in Dominican amber. Fossil Record, 18:3135.

Poinar, G.O., Jr. and Legalov, A.A. 2015b. New Apioninae (Coleoptera: Brentidae) in Dominican amber. Historical Biology, 26:603-607.

Poinar G.O., Jr. and Legalov, A.A. 2015c. New Curculioninae (Coleoptera: Curculionidae) in Dominican amber. Palaeontologia Electronica 18.1.13A:1-15 palaeo-electronica.org/content/2015/1101-new-curculioninae

Poinar G.O. and Legalov, A.A. 2015d. Two new species of the genus Rhynchitobius Sharp, 1889 (Coleoptera: Rhynchitidae) in Dominican amber. Annales de la Société entomologique de France (N.S.), 51:70-77.

Poinar, G.O., Jr. and Legalov, A.A. 2015e. New species of the subfamily Cossoninae (Coleoptera: Curculionidae) in Dominican amber. Historical Biology, 27:491502.

Poinar, G.O., Jr. and Legalov, A.A. 2015f. New species of the genera Dryophthorus Germ. and Stenommatus Woll. (Coleoptera: Dryophthoridae) in Dominican amber. Historical Biology, 27:508-513. 
Poinar, G.O., Jr., Legalov, A.A., and Brown, A.E. 2013. Brachycamacina, a new subtribe of the tribe Naupactini (Coleoptera: Curculionidae: Entiminae) in Dominican amber. Palaeontologia Electronica 16.3.24A:1-9 palaeo-electronica.org/content/2013/531-new-weevil-tribe

Poinar, G.O., Jr. and Mastalerz, M. 2000. Taphonomy of fossilized resins: determining the biostratinomy of amber. Acta Geologica Hispanica, 35:171-182.

Poinar, G.O., Jr. and Poinar, R. 1999. The Amber Forest. Princeton University Press, Princeton, New Jersey.

Rheinheimer, J. 2004. Illustrierter Katalog und Bibliographie der Anthribidae der Welt (Insecta: Coleoptera). Mitteilungen des Entomologischen Vereins Stuttgart, 39:1-288. (in German)

Say, T. 1831. Descriptions of new species of Curculionites of North America, with observations on some of the species already known. New Harmony, Indiana.

Schaeffer, C. 1904. New genera and species of Coleoptera. Journal of the New York Entomological Society, 12:197-236.

Schlee, D. 1990. Das Bernstein-Kabinett. Begleitheft zur Bernsteinausstellung im Museum am Löwentor, Stuttgart, 28:1-100. (In German)

Schoenherr, C.J. 1823. Curculionides [Tabula synoptica familiae Curculionidum]. Isis von Oken, 1823:11321146. (In Latin)

Schoenherr, C.J. 1826. Curculionidum dispositio methodica cum generum characteribus, descriptionibus atque observationibus variis seu Prodromus ad Synonymiae Insectorum, partem IV. Lipsiae, Fleischer. (in Latin)

Schoenherr, C.J. 1833. Genera et species curculionidum, cum synonymia hujus familiae. Species novae aut hactenus minus cognitae, descriptionibus a Dom. Leonardo Gyllenhal, C.H. Boheman, et entomologis aliis illustratae. Vol. 1(1). Roret, Paris. (in Latin)
Solórzano Kraemer, M.M. 2007. Systematic, palaeoecology, and palaeobiogeography of the insect fauna from Mexican amber. Palaeontographica, A(282):1133.

Soriano, C., Gratshev, V.G., Delclos, X. 2006. New Early Cretaceous weevils (Insecta, Coleoptera, Curculionoidea) from El Montsec, Spain. Cretaceous Research, 27:555-564.

Valentine, B.D. 1960. The genera of the weevil family Anthribidae North of Mexico (Coleoptera). Transactions of the American Entomological Society, 86:4185.

Valentine, B.D. 1972. Notes on Anthribid weevils. III. New species and records primarily from Arizona (Coleoptera: Anthribidae). Coleopterists Bulletin, 26:1-12.

Valentine, B.D. 1982. A new endemic genus of Anthribid weevil from Jamaica (Anthribidae: Araecerini). Coleopterists Bulletin, 36:197-199.

Valentine, B.D. 1999. A review of Nearctic and some related Anthribidae (Coleoptera). Insecta Mundi, 12: 251-296.

Valentine, B.D. 2003. A catalogue of West Indies Anthribidae (Coleoptera). Insecta Mundi, 17: 49-67.

Waterhouse, G R. 1845. Descriptions of Coleopterous Insects collected by Charles Darwin, Esq., in the Galapagos Islands. Annals and Magazine of Natural History, 16:19-41.

Zherikhin, V.V. 1993. Suborder Polyphaga, p. 20-37. In Gromov, V.V., Dmitriev, V.Yu., Zherikhin, V.V., Lebedev, E.L., Ponomarenko, A.G., Rasnitsyn, A.P., and Sukatsheva, I.D. (eds.), Mesozoic Insects and Ostracodes of Asia. Nauka, Moscow. (In Russian)

Zimmermann, E.C. 1971. Mexican Miocene amber weevils (Insecta: Coleoptera: Curculionidae). University of California Publications in Entomology, 63:103-106. 


\section{APPENDIX}

Key to species of the genus Piesocorynus in Dominican and Mexican amber.

1. Elytron with tubercles on third interval

- Elytron without tubercles on third interval

2. Elytron with one tubercle at base of second and third intervals ---P. unibullus sp. nov.

- Elytron with two or three tubercles on third interval

3. Elytron with two tubercles on third interval: one at base and one in middle

P. bibullus sp. nov.

- Elytron with three tubercles: one at base of second and third intervals, one in middle and one before apex of third interval

P. tribullus sp. nov.

4. Antennae long, extending beyond humeri

5

- Antennae short, not reaching, or reaching humeri

5. Elytra short. Pronotum elongate with sides evenly rounded

- Elytra elongate. Pronotum short with sides angular in middle

6. Pronotum elongate. Elytra 1.4 times as long as pronotum

- Pronotum short. Elytra 1.6-2.0 times as long as pronotum

7. Elytra approximately equal in length and width

- Elytra considerably longer than wide (1.3-1.4 times)

8. Body size large $(4.8 \mathrm{~mm})$. Punctures in striae of elytra large. Pronotum slightly longer than wide.

- Body size smaller $(2.5 \mathrm{~mm})$. Punctures in striae of elytra fine. Pronotum transverse

$P$. brevitectus sp. nov.

$P$. hamus sp. nov. $P$. elongatus sp. nov

P. parategus sp. nov.

$P$. villosus sp. nov.

P. parvocorpus sp. nov. 